\title{
CFD ANALYSIS OF THE FLUID PARTICLES DISTRIBUTION BY MEANS OF AVIATION TECHNIQUE
}

\author{
Tomasz Seredyn ${ }^{*}$, Adam Dziubiński**, Piotr Jaśkowski ${ }^{* * *}$ \\ * Polish Air Force Academy, Dywizjonu 303 35, 08-521 Dęblin, Poland \\ ** Centre of New Technologies, Institute of Aviation, al. Krakowska 110/114, 02-256 Warsaw, Poland \\ *** Design Analysis \& Calculation Group, PZL „Warszawa - Okęcie” S.A. Airbus Defence \& Space, \\ al. Krakowska 110/114, 02-256 Warsaw, Poland \\ t.seredyn@wsosp.pl,adam.dziubinski@ilot.edu.pl,piotr.jaskowski@pzl.eads.net
}

\section{Abstract}

The article describes a computational study, using CFD models, ofdropletspray dispersal in the wake of a 'Turbo Kruk' airplane up to $500 \mathrm{~m}$ downstream. The CFD Reynolds-averaged Navier-Stokes (RANS) models use a Lagrangian (droplet phase) and Eulerian (fluid phase) procedure to predict the droplet trajectories trough the turbulent aircraft wake. The methods described in the work have the potential to improve current models for aerial spraying and will help in the development of new spraying procedures. In this study, the CFD models are used to describe the phenomenon of sprays released from atomizers mounted on the plane. A parametric study of the aircraft model examines the effects of crosswind on the aircraft's vortex structures and the resulting droplet trajectories. The study shows, that such influence is underestimated in the current models. A comparison of the present results to AGDISP predictions is provided.

Keywords: Droplets dispersion modeling, Pesticide spraying, Agricultural aircraft wake.

\section{INTRODUCTION}

The spread of various substances by the aircraft takes place in many areas of human life, from military applications, the protection of forests to agricultural aviation. It should be mentioned, that a very large and very substantial amount of aircraft are employed in the crop protection treatment, as well as in the management of forests. Chemical agents are most commonly used, due to their high degree of effectiveness, in killing the pests, the weeds, and curing the diseases at relatively low costs [31].

However, one of the fundamental limitations in the application by means of this technique is the chance of chemical agent drift [32]. By drift authors mean the unintentional movement and settlement of agents, outside the area being treated. 
Theoretical analysis and experimental research, on this natural occurrence, has previously been associated not only with aviation, but also within other applications. It should be noted, that from the scientific point of view, the phenomenon of the movement and settling of droplets is very interesting and not fully explained, largely because it is difficult to describe mathematically. On one hand, this process should take into account the disturbance velocity field that follows the aircraft. However, on the other hand, the motion of a cloud of droplets in a turbulent atmosphere is subjected to other factors, such as wind, specified temperature, humidity and the evaporation of droplets, all of which complicates the analysis. The initial droplet-size spectrum, along with the aircraft wake effect and atmospheric conditions, will dictate the spatial distribution of droplets on a given target area.

Analysis may provide benefits, such as recognition and a mathematical description of the phenomena, associated with the movement and distribution of droplets dispersed in the air. Based on results, the improvement of technical equipment and associated technologies, used in the dispersal of chemical agents by aircraft, could be achieved.

For the past fifty years, many theoretical models and a large data-collection effort has been undertaken, especially by the United States Department of Agriculture (USDA) Forest Service to develop and validate models, able to predict the behavior of spray from the air [39, 41]. In the 1970s, researchers focused on Gaussian plume models, which predicted the dispersal of a steady-state spray plume, using the exponential decay of droplet concentration, in three-dimensional space. Based on Gaussian assumptions, the Forest Service Cramer Barry Grim (FSCBG) model was developed by the USDA Forest Service and the U.S. Army, for aerial pesticide spraying $[9,12]$. Most researchers agree, that such modeling is more suited to long-range drift $(0.5$ to $10 \mathrm{~km})$ and does not provide sufficient resolution of the problem in representing the aircraft equipment and near-wake flow dynamics [38, 37].

From the 1980s until now, the development of Lagrangian droplet trajectory models has been suggested. Experimental research and the revolution in computer technology have enabled better modeling of aircraft vortex wakes and the tracking of droplets within them. This, has ultimately led to the development of the Lagrangian AGricultural DISPersal (AGDISP) model, which has become the industry standard $[41,37]$. AGDISP was developed by the USDA Forest Service and is based on equations of motion, governing the behavior of droplets in fluid. Unfortunately, the AGDISP model includes a simple, analytical basis, quantifying vortex swirling, propeller effects, local wind speed, gravity and atmospheric turbulence. Some improvements of the model have been made. For example: better evaporation and time-stepping algorithms and improved representation of the droplet-size spectrum. However, the most important limitations of AGDISP are connected to a very simple representation of the wakes produced by an airplane. Nonetheless, the Lagrangian models are more capable of capturing the near-wake flow field effects of aircraft than the Gaussian approach.

The first study, taking into account the impact of disturbances on the motion of droplets and their distribution, was a National Advisory Committee for Aeronautics (NACA) Report of 1954, prepared by Reed [30]. He considered trajectories of droplets, from a plane, perpendicular to the direction of the flight, assuming that the droplets' movement in the velocity field is induced by free vortices, modeled by two, infinitely long vortex lines, which interact with each other in time. This author assumed the spectrum of atomized droplets, satisfies a normal distribution.

Subsequent authors, such as Аеревянко [10] or Kamiński [21] developed this theory, considering a bi-plane system. They assumed two pairs of horseshoe vortices [22], which took into account the influence of the propeller slipstream and cross winds. Moreover, Kamiński included the evaporation of droplets. These issues were also addressed in further scientific research, such as $[4,7,44]$. This research focused 
on the Lagrangian trajectory model, which is AGDISP [4]. An extensive field study [19] and model validation effort [5], confirmed the predictive capability of the Lagrangian computational engine, that drove the model [39] to approximately 500 $\mathrm{m}$ downwind [38]. In Poland, an elaborate model of spraying from aircraft was suggested by Pietruszka [28], who developed the most appropriate vortex-swirling theory.

During the same period, other researchers independently developed their own spray-drift models or contributed essential parts of the modeling process. These models are shown in $[45,3,42,16,2$, $17,20,34,43]$.

\section{AIM AND THEORETICAL BACKGROUND}

The aim of this study is to present the mathematical models that describe the physics of the spread and distribution of the atomized liquid droplets, in the air, by aircraft. Based on analysis of the models, the quality and usefulness of these theories, in fieldwork and any possible indications of future directions of research, will be considered.

As has been said in previous articles [31], the movement of droplets in the air can be divided into 4 phases:

- PHASE I - droplet movement at high speed, given to them by the spray device and aircraft velocity.

- PHASE II - drops fall at a speed of sedimentation, which overlaps the disturbance velocity field following the aircraft and the movement of air masses caused by wind, turbulence and convection.

- PHASE III - occurs after the termination of flight disruptions, caused by the aircraft. During this time, their (droplets) movement is subjected to the forces of gravity, aerodynamic drag and the movement of air masses.

- PHASE IV - associated with the growing penetration of droplets, in the form of subsidence or reflection.

\subsection{Models of movement and distribution of droplets}

These models of movement and the distribution of droplets can be divided into two groups:

1. Not taking into account disturbance fields following the aircraft on the movement and distribution of liquid droplets. These models are called 'free'.

2. Taking into account this factor, as well as other parameters, affecting the trajectory of a particle, called the 'fixed' models.

In this study, as already mentioned, 'fixed' models are considered and their potential implementation as a computer program, enabling the estimation of droplet dispersal on the ground.

\section{ANALYSIS OF SELECTED 'FIXED' MODELS}

The flight of any aircraft results in a disturbance of the flow field, in a large area of its flight path. This is due to the turbulence field generated by the wings, tail-plane and propeller slipstream. In further distances behind the plane, the vorticity is concentrated into two vortices, at a distance of about 0.8 of a wingspan to one another. The energy of these disturbances makes it necessary to take into account their effect on spray droplet trajectories. These trajectories depend mainly on the droplet sizes and the position of the nozzle along the wing. 
As was said previously, it seems that few assumptions in the models are necessary, for example these, proposed by Pietruszka [27]. They appropriately describes the physics of the dispersal and distribution processes of spraying [28]. The models should adopt the following assumptions:

1. The disturbance velocity field, appearing behind a plane, is generated by the vortex wake that flows down from the wings and propeller. The wake of the wing is modeled by inviscid, incompressible flow, calculated by means of vortex lines.

2. It is assumed, that in the propeller slipstream, there is an additional, potential velocity field, generated by the vortex, that flows from the axis of the propeller and a narrow vortex layer, flows down from the perimeter of the propeller. This takes into account the movement of the vortex from the axis of the propeller and deformation of the propeller vortex layer, due to its interference with the wing.

3. The velocity field is additionally modified by influence of the near ground.

4. Droplet evaporation is taken into account as a semi-empirical formula [29].

5. The effect of a wind is taken into account, by adopting a logarithmic profile and canopy height.

In comparison with the model proposed by Pietruszka, in AGDISP, the flow field after the aircraft is very simplified and the model has some foundations. When an aircraft flies at constant altitude and speed, the aerodynamic lift, generated by its lifting surfaces, equals the aircraft's weight. The majority of the lift is carried by the wings, which generate one pair of swirling masses of air (vortices) downstream of the aircraft. The rollup of this trailing vorticity is approximated as occurring immediately downstream of the wing and the local swirl velocity, around each of the two vortices, is given by

$$
v=\frac{\Gamma}{2 \pi} \frac{r}{\max \left(r, r_{c}\right)^{2}},
$$

where, $\Gamma$ is the vortex circulation strength, given by

$$
\Gamma=\frac{2}{\pi} \frac{W}{\rho_{a} s U_{\infty}},
$$

$r$ is the distance from the vortex center to the droplet position, $r_{c}$ is the vortex core radius, $W$ the aircraft weight, $s$ is the aircraft's semispan and $U_{\infty}$ the aircraft speed. The vortex strength decays with time, because of atmospheric turbulence, following a simple decay model

$$
\Gamma=\Gamma_{i} \exp \left(-\frac{b q t}{s}\right)
$$

$\Gamma_{i}$ is the initial vortex circulation strength and $b q$ has velocity meaning and depends on the physical situation.

As stated earlier, the second model, that takes into account spraying from the aircraft, will be discussed in the next step, with a presentation of the basics of the analysis done by Pietruszka [27]. The main focus will be on the description of the velocity field, generated by an airplane. 


\subsection{Velocity field behind aircraft}

The velocity disturbance field behind the aircraft can be determined as a vector sum of three velocities - the stream flowing down from the wing, the stream behind the propeller and the wind. The resulting velocity field can therefore be defined by the equation

$$
\vec{v}=\overrightarrow{v_{1}}+\overrightarrow{v_{2}}+\overrightarrow{v_{3}}
$$

\subsubsection{Airflow from the wing}

The wing is treated as a lifting surface, in an incompressible, steady and potential flow, extending over the entire surface of the fuselage. Of course, the wing - fuselage interference should be analyzed, according to the theory of flow around a slender body, as specified in the following paper [1]. Vortex line distribution is determined by means of the vortex lattice method, presented in the work of Miranda et al. [24]. The impact of the ground can be taken into account in the form of a mirror image [18]. More about the calculation can be found in [22].

\subsubsection{Propeller stream}

The rotating propeller induces an additional velocity field, which can be expressed in the similar way as the airflow from the wing.

\subsubsection{Wind}

The wind direction can be considered as parallel or perpendicular to the flight velocity vector. The perpendicular direction of the wind causes drift. The influence of area coverage on the wind velocity profile is explained more precisely in [15].

\section{MOTION OF DROPLETS}

Sprayed droplets, with a high, initial velocity, have a significant distribution of diameters, within the range of few to several hundred $\mu \mathrm{m}$ (depending on the type of sprayers). This corresponds to Reynold's numbers, with respect to their sedimentation velocity, of $0.1 \leq \mathrm{Re} \leq 100$. According to the work of Boothroyd [6], drag force acting on the droplet versus the Reynolds number can be presented in the form

$$
C_{D}=\left\{\begin{array}{c}
0.424 R e \geq 1000 \\
\frac{24}{R e}\left(1+0,16 R e^{0.667}\right) 0.5<R e<1000 \\
\frac{24}{R e}+4.5 R e \leq 0.5
\end{array} .\right.
$$

For this range of Reynold's numbers, an error in the drag coefficient does not exceed $6 \%$. The equation of droplet motion, in its general form, can be written as 


$$
\frac{d}{d t}\left(m \dot{\overrightarrow{R_{d}}}\right)=m \vec{g}+\overrightarrow{F_{D}}+\overrightarrow{F_{A}}+\overrightarrow{F_{M}}+\overrightarrow{F_{B}}
$$

where, is the mass of a droplet, while ,,, are aerodynamic drag force, buoyancy force and Magnus and Basset forces, respectively. In the present form of motion, the last three forces are omitted, without significantly affecting the results of the calculations.

The general equation of droplet motion [8], after transformation, has the form

$$
\frac{d v_{d}}{d t}=\vec{g} \frac{\left(\rho_{d}-\rho_{a}\right)}{\rho_{d}}+\frac{\vec{v}-\overrightarrow{v_{d}}}{\tau_{T}}
$$

where

$$
\tau_{T}=\frac{24}{c_{D} R e} \frac{\rho_{d} d_{d}^{2}}{18 \mu}
$$

is the relaxation time. This equation is solved having given the velocity field of the air around droplets [26], [27]. The trajectory equation can be solved as well using the implicit and the trapezoidal schemes, where the new location of a droplet is given in the form. More details can be found in [8].

The evaporation of droplets is given in the formula

$$
m_{d}(t+\Delta t)=m_{d}(t)-N_{i} A_{d} M_{w, i} \Delta t
$$

where $A_{d}$ is the droplet surface, $M_{w, i}$ is the molecular weight and $N_{i}$ - molar flux of vapour given in the form

$$
N_{i}=k_{c}\left(c_{i, s}-c_{i, \infty}\right) \text {. }
$$

Here $c_{i, s}$ and $c_{i, \infty}$ is the vapour concentration at the droplet surface and the vapour concentration in the bulk gas, respectively. $k_{c}$ can be received from the equation

$$
\frac{k_{c} d_{d}}{D_{i, m}}=2+0.6 R e^{1 / 2} S c^{1 / 3}
$$

where the Schmidt number has the form for the diffusion coefficient of vapour in the bulk $D_{i, m}$.

\section{OBJECT OF RESEARCH}

The object of the study is the PZL-106 'Turbo Kruk', equipped with apparatus for ULV spraying in the form of 8 rotating sprayers (atomizers), used in chemicalization treatment [46]. For the study, it has been assumed an altitude of the flight equals to $\mathrm{h}=2 \mathrm{~m}$ (between the aircraft's atomizers and the ground) and a speed corresponding to the most commonly used in such a treatment $\mathrm{v}_{\mathrm{r}}=50 \mathrm{~m} / \mathrm{s}$. 
Table 1. Technical data of the Turbo Kruk airplane

\begin{tabular}{|l|c|}
\hline Propeller radius & $1.25 \mathrm{~m}$ \\
\hline Length & $10.2 \mathrm{~m}$ \\
\hline Boom height & $-0.3048 \mathrm{~m}$ \\
\hline Weight & $-2500 \mathrm{~kg}$ \\
\hline Height & $3.8 \mathrm{~m}$ \\
\hline Propeller RPM & -2500 \\
\hline Flight altitude & $2 \mathrm{~m}$ \\
\hline
\end{tabular}

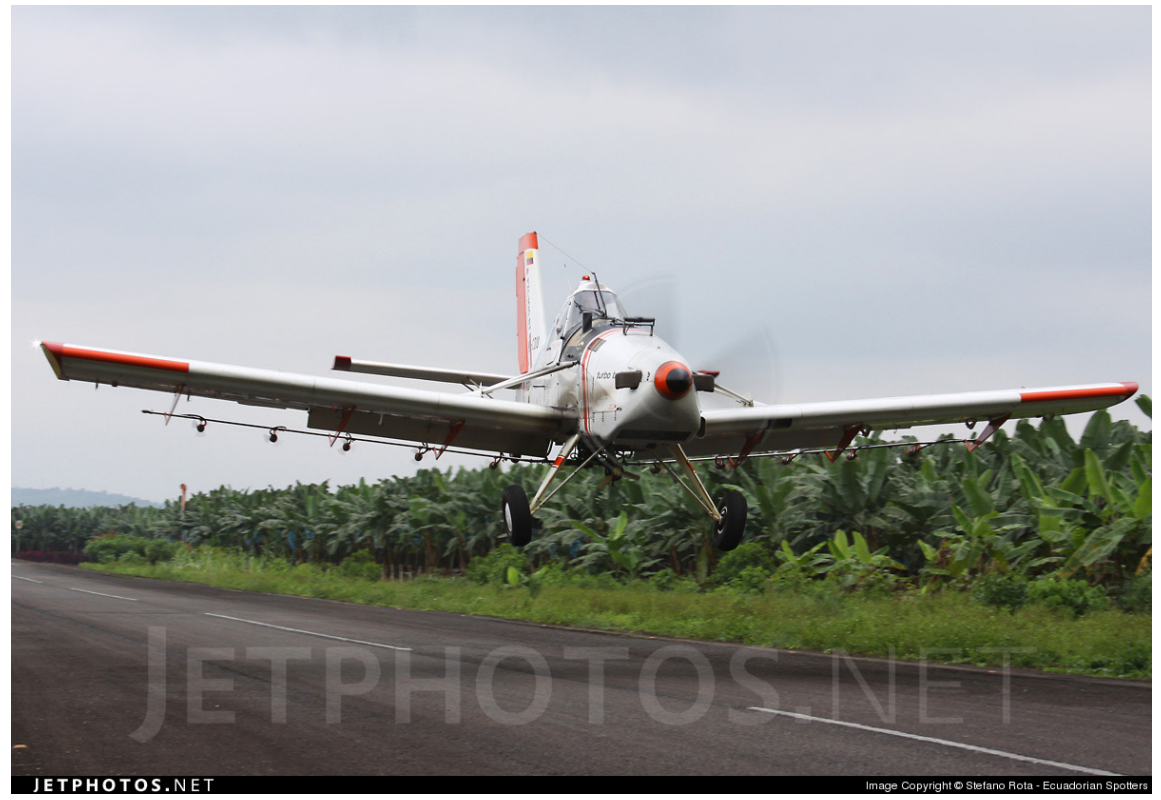

Fig. 1. Turbo Kruk with the equipment [47]

The computational model of the plane is a three-dimensional full-scale model of the 'Turbo Kruk' designed using ANSYS 16.2 ICEM CFD code [8]. In order to simplify the geometry, certain components of lesser significance were not included, such as the exhaust vanes, the horizontal stabilizer struts, the wire-cutting knife on a cabin windshield, a sprayer pump and other components of the plane [13].

The geometry of the model can be seen in the Figure 2. To visualize the atomizer construction, a picture of the one - AU4000 of Micronair, is depicted in the Figure 3. The fluid domain is given in the Figure 4 where the dimensions of the domain are: $600 \mathrm{~m}$ long, $160 \mathrm{~m}$ wide and $33 \mathrm{~m}$ height. The total volume is $3,168,000 \mathrm{~m}^{3}$. The domain was meshed as shown in Figure 5. It contains over $7.5^{*} 10^{6}$ cells with the unstructured mesh containing tetra-shaped elements mainly. The mesh is refined around the airplane to ensure accurate resolution in these regions. During the calculations, the mesh was refined again in these regions, where it was necessary to strictly predict the flow behind the plane according to the appearance of swirls and droplets. 


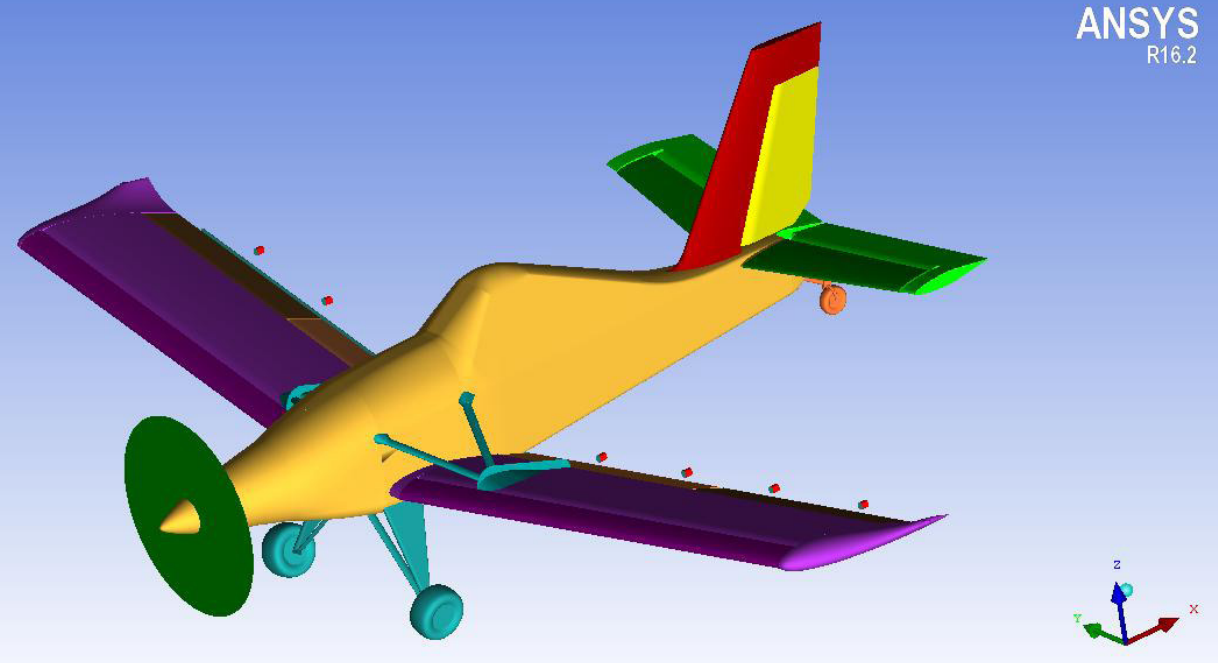

Fig. 2. The geometry of the plane [13]

The domain boundaries allow the flow to enter or exit the domain, depending on the local flow direction. All sides act as a far field with specified velocity conditions that impose the wind, but the one, which acts as an outlet. The flow simulations have been computed using Reynolds-averaged Navier-Stokes (RANS) equations solver based on the finite volume method. A commercial code, ANSYS Fluent, has been chosen for this purpose [8]. The set of gas phase governing equations (steady state) is given below in the Table 2 .

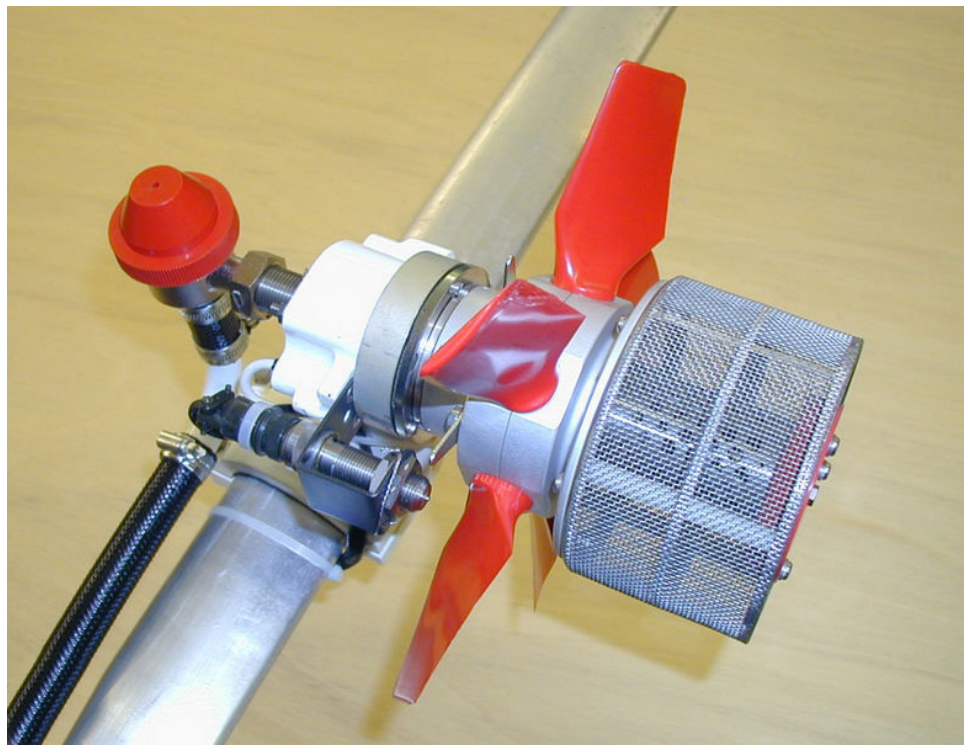

Fig. 3. AU4000 atomizer [47] 


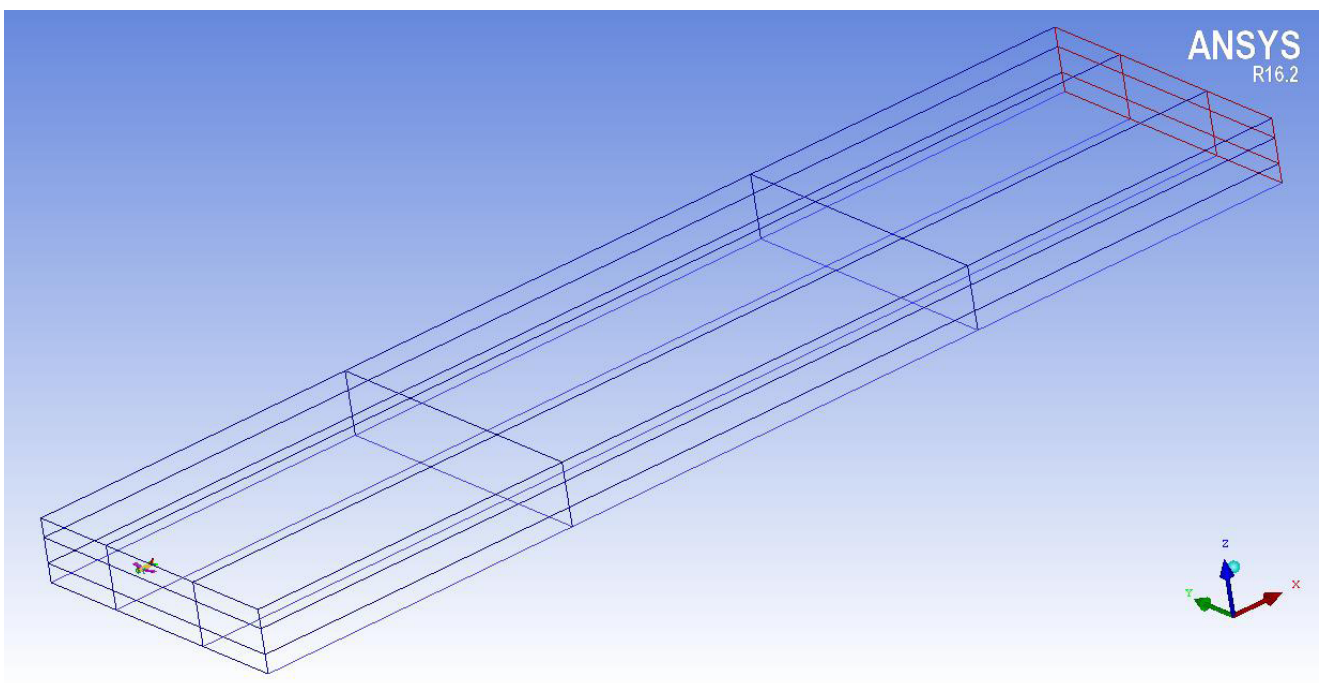

Fig. 4. The geometry of the domain

Table 2. Gas phase governing equations

\begin{tabular}{|l|c|c|c|}
\hline \multirow{2}{*}{ Main equation } & \multicolumn{3}{|c|}{$\frac{\partial\left(v_{j} \rho \emptyset\right)}{\partial x_{j}}=\frac{\partial(\Gamma \emptyset)}{\partial x_{j} \partial x_{j}}+S_{\emptyset}$} \\
\hline \multirow{2}{*}{ Mass } & $\emptyset$ & $\Gamma$ & $S_{\emptyset}$ \\
\cline { 2 - 4 } & 1 & 0 & 0 \\
\hline \multirow{2}{*}{ Momentum } & $v_{i}$ & $\mu$ & $-\frac{\partial p}{\partial x_{i}}-\frac{\partial\left(\rho \overline{v_{i}^{\prime} v_{j}^{\prime}}\right)}{\partial x_{j}}$ \\
\hline
\end{tabular}

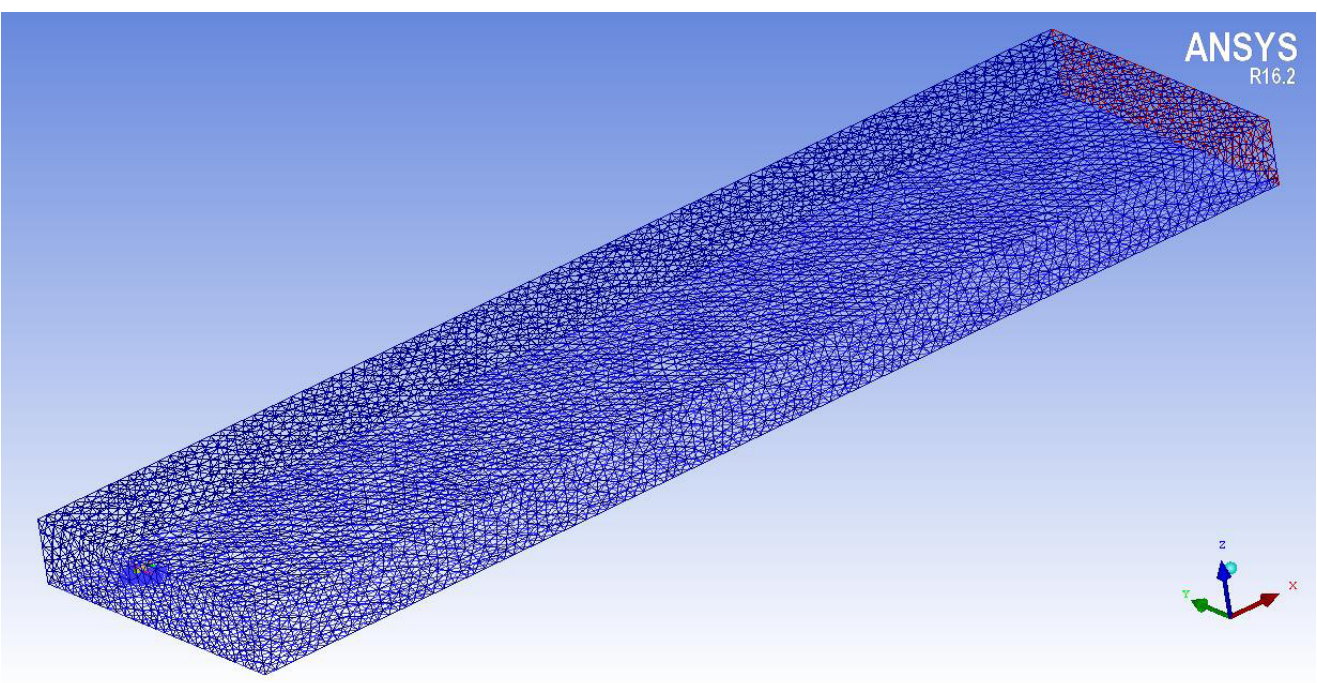

Fig. 5. The mesh of the domain 
The main set of governing equations has been closed with Menter K- $\omega$ SST 4-equations turbulence model, more adequate in terms of the flow turbulization behind the aircraft prediction [8, 14]. Since the pressure farfield condition was used on fluid boundary of the domain, the ideal gas model of density, as demanded by this condition, was also assumed. Discrete phase was chosen as interacting with continuous phase and droplets diameter distribution was represented by Rosin-Ramler distribution with total flow rate $1.378 \mathrm{~kg} / \mathrm{s}$.

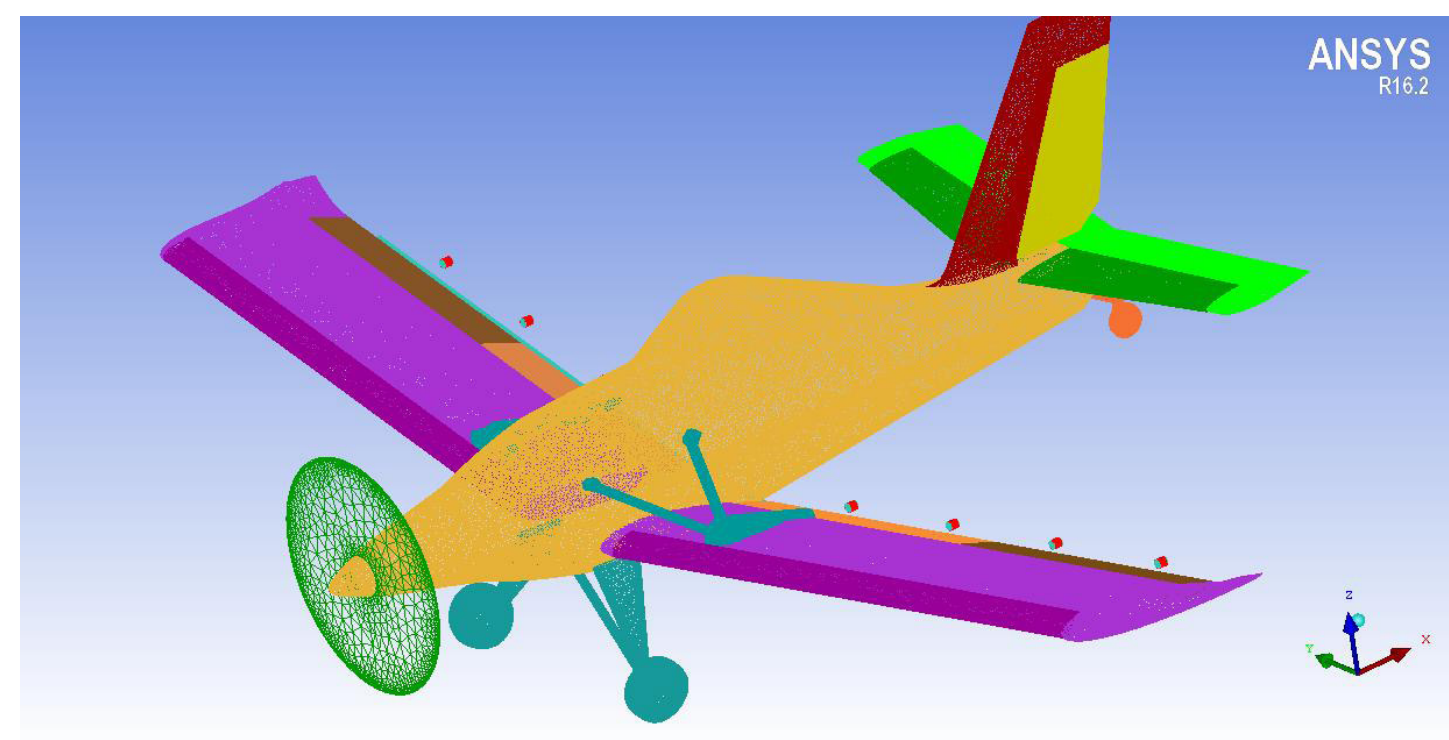

Fig. 6. The refined mesh around the plane [13]

\section{RESULTS}

The theoretical models should be useful for predicting the behavior of spray released from aircraft and be able to calculate the distribution of the mass aimed at the target field. The AGDISP model was shown to overpredict deposition rates, relative to experimental field data $[11,5]$, although recent improvements have allowed the latest version of AGDISP to match field data [40]. However, the study shows that the mass distribution generated by AGDISP software [48] does not exactly match the distribution received during field experiments, in Poland.

Figure 7. presents a comparison of the theoretical calculations and data, collected during field experiments, carried out at the research training ground of the Academy of Agriculture and Technology, which the experimental data was presented in the study by Seredyn et al. [35]. The analysis was done using a $30 \%$ water solution of urea, with an additional $2 \%$ of nigrosine, with settings for a $20.23 \mathrm{dm}^{3} /$ ha dose. Atmospheric conditions were measured as: wing velocity $-5.1 \mathrm{~m} / \mathrm{s}$, temperature $-290.2 \mathrm{~K}$ and humidity $-65 \%$. As far as the helicopter was concerned, the following conditions occurred for a PZL Świdnik Mi-2 airplane: flight velocity $-22.8 \mathrm{~m} / \mathrm{s}$; flight height $-5 \mathrm{~m}$ and two sprayers on the boom [23]. 


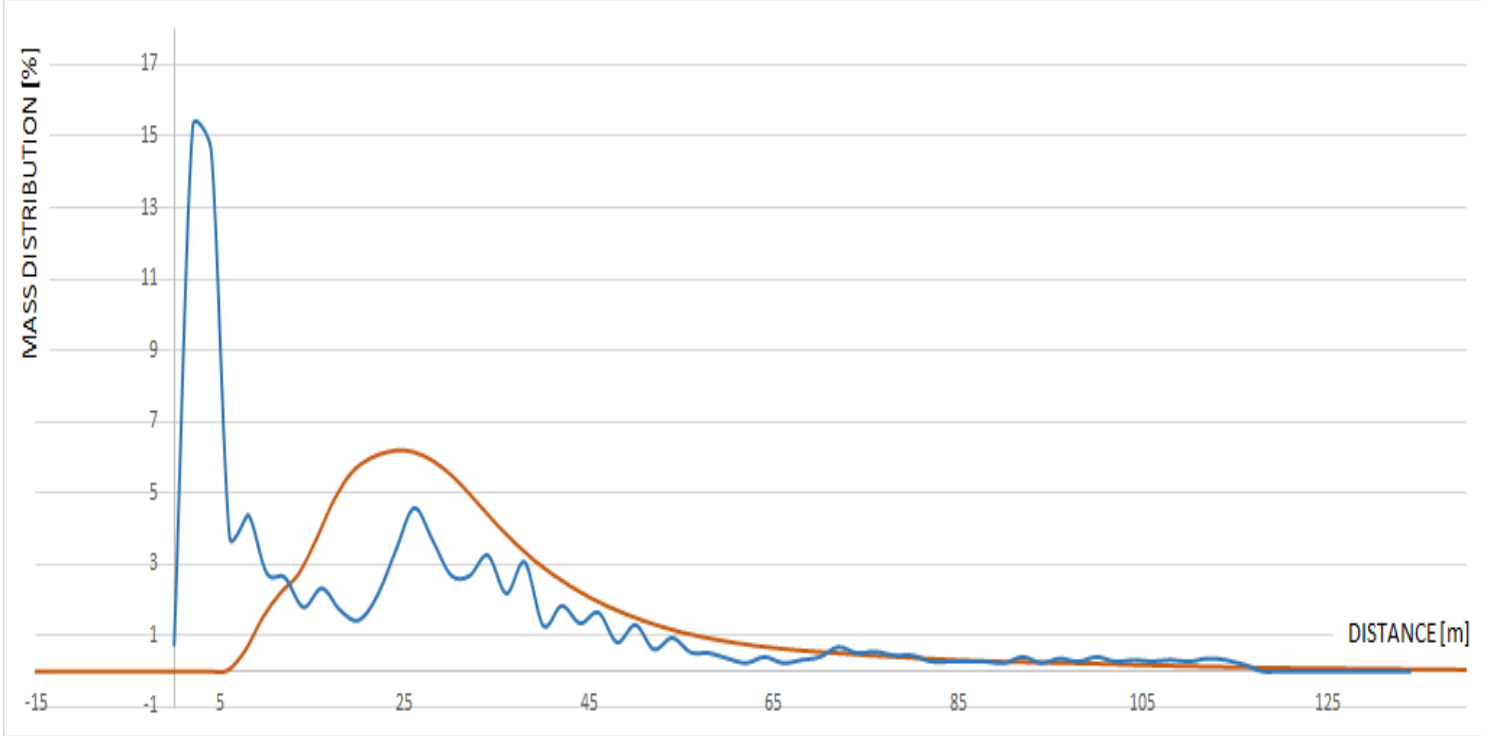

Fig. 7. Mass distribution for a Mi-2 helicopter: the orange line - AGDISP, the blue line - field test

From the above figure it is seen, that a greater amount of mass is moved downwind in the experimental case, compared to AGDISP model predictions. This means, that the influence of very intensive air turbulence, generated by an aircraft during the flight [36], must be recognized in a more appropriate way, as a major cause of droplets being pushed outwardly from the flight path [25].
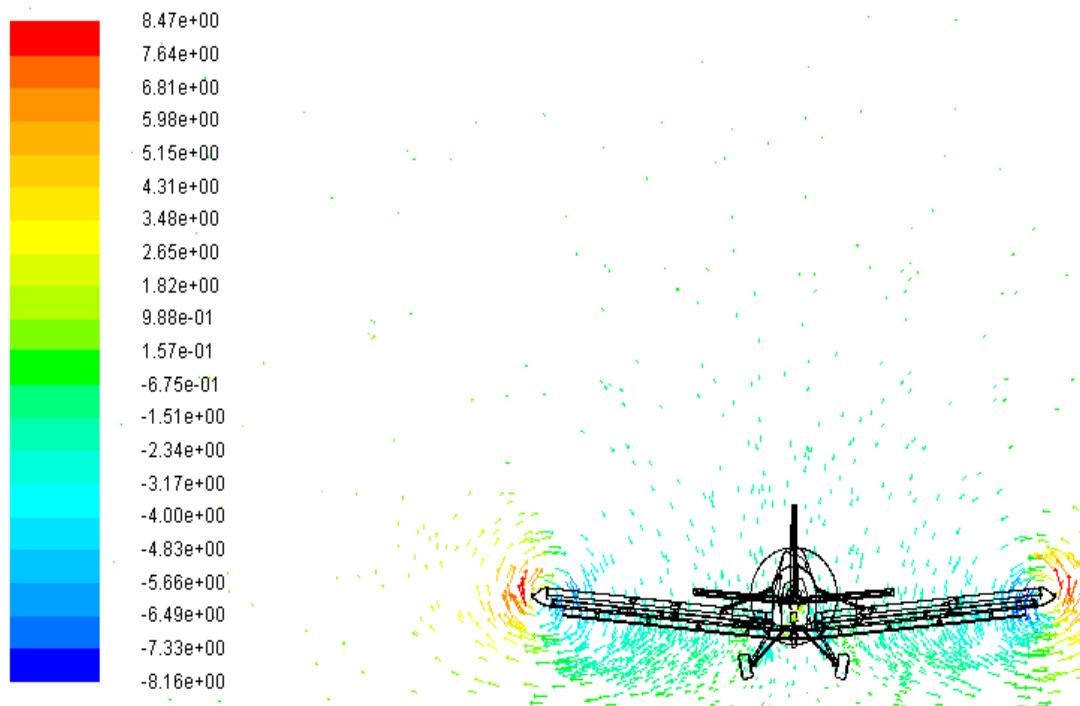

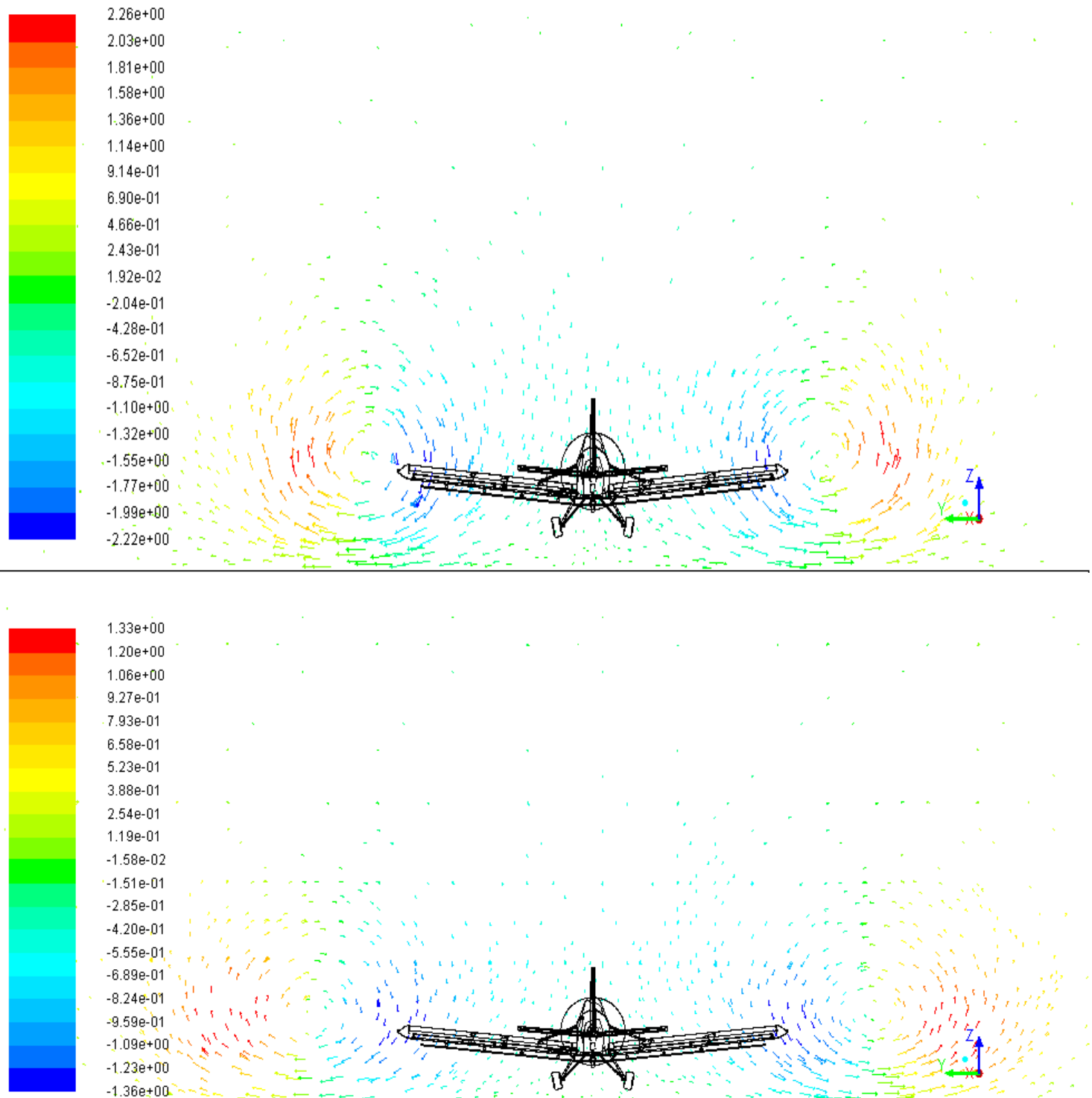

$1.33 \mathrm{e}+00$

$1.20 \mathrm{e}+00$

$1.06 \mathrm{e}+00$

$9.27 \mathrm{e}-01$

$7.93 \mathrm{e}-01$

$6.58 \mathrm{e}-01$

$5.23 \mathrm{e}-01$

$3.88 \mathrm{e}-01$

$2.54 \mathrm{e}-01$

$1.19 \mathrm{e}-01$

$-1.58 \mathrm{e}-02$

$-1.51 \mathrm{e}-01$

$-2.85 \mathrm{e}-01$

$-4.20 \mathrm{e}-01$

$-5.55 \mathrm{e}-01$

$-6.89 \mathrm{e}-01$

$-8.24 \mathrm{e}-01$

$-9.59 \mathrm{e}-01$

$-1.09 \mathrm{e}+00$

$-1.23 \mathrm{e}+00$

$-1.36 \mathrm{e}+00$

Fig. 8. Vectors of the air velocities in three planes perpendicular to the aircraft velocity in 10 , 100 and 200 meters without the wind 
Due to this discrepancy, the study of the described situation is done by means of the CFD methods for another aircraft, which is the PZL-106 'Kruk'. According to authors' opinion, this method is the most appropriate and powerful way to analyze particles spraying by means of aviation technique. The CFD calculations showed a better similarity of the predictions to the data, collected during the field experiments as well as revealed some drawbacks of the AGDISP predictions.
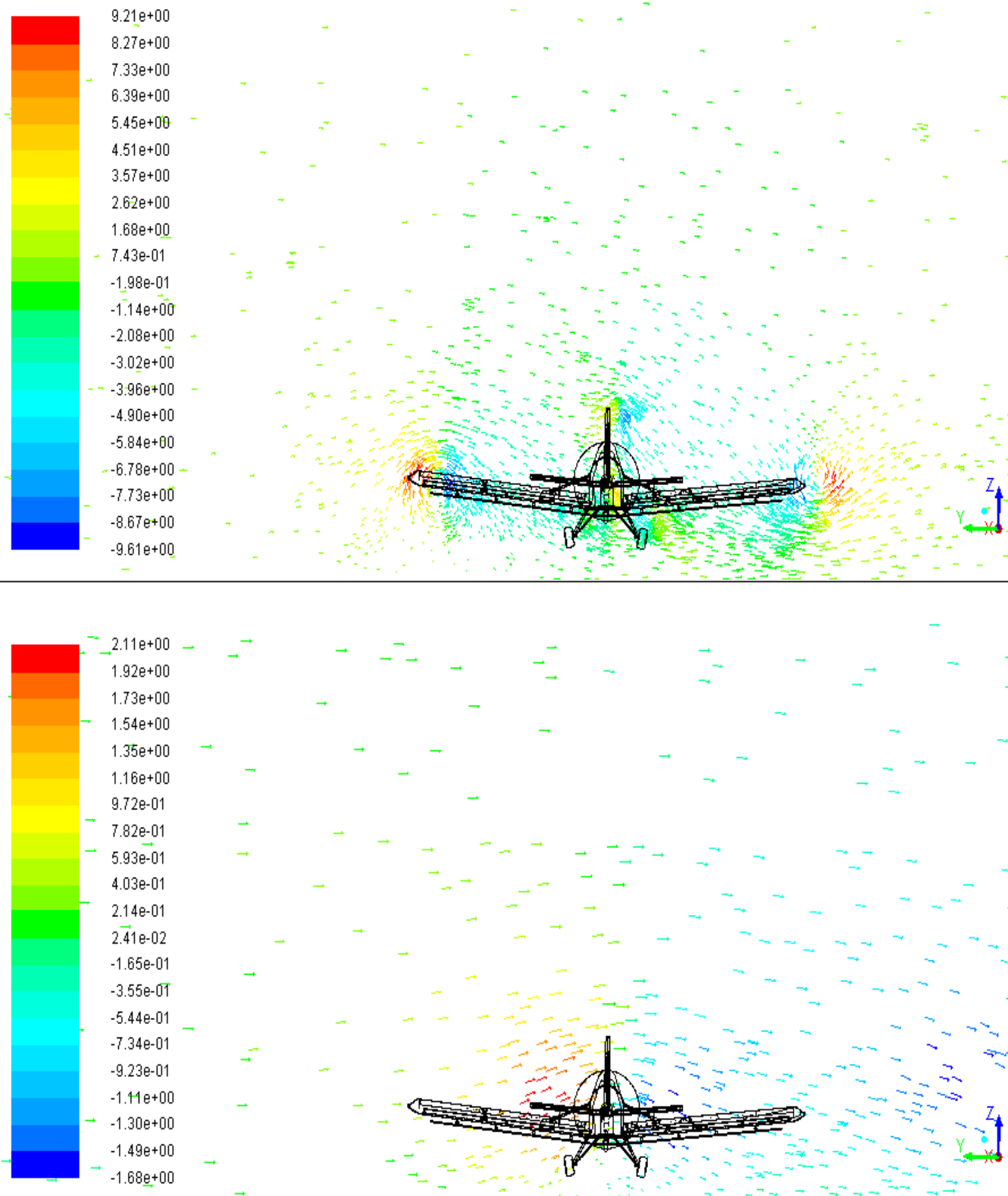


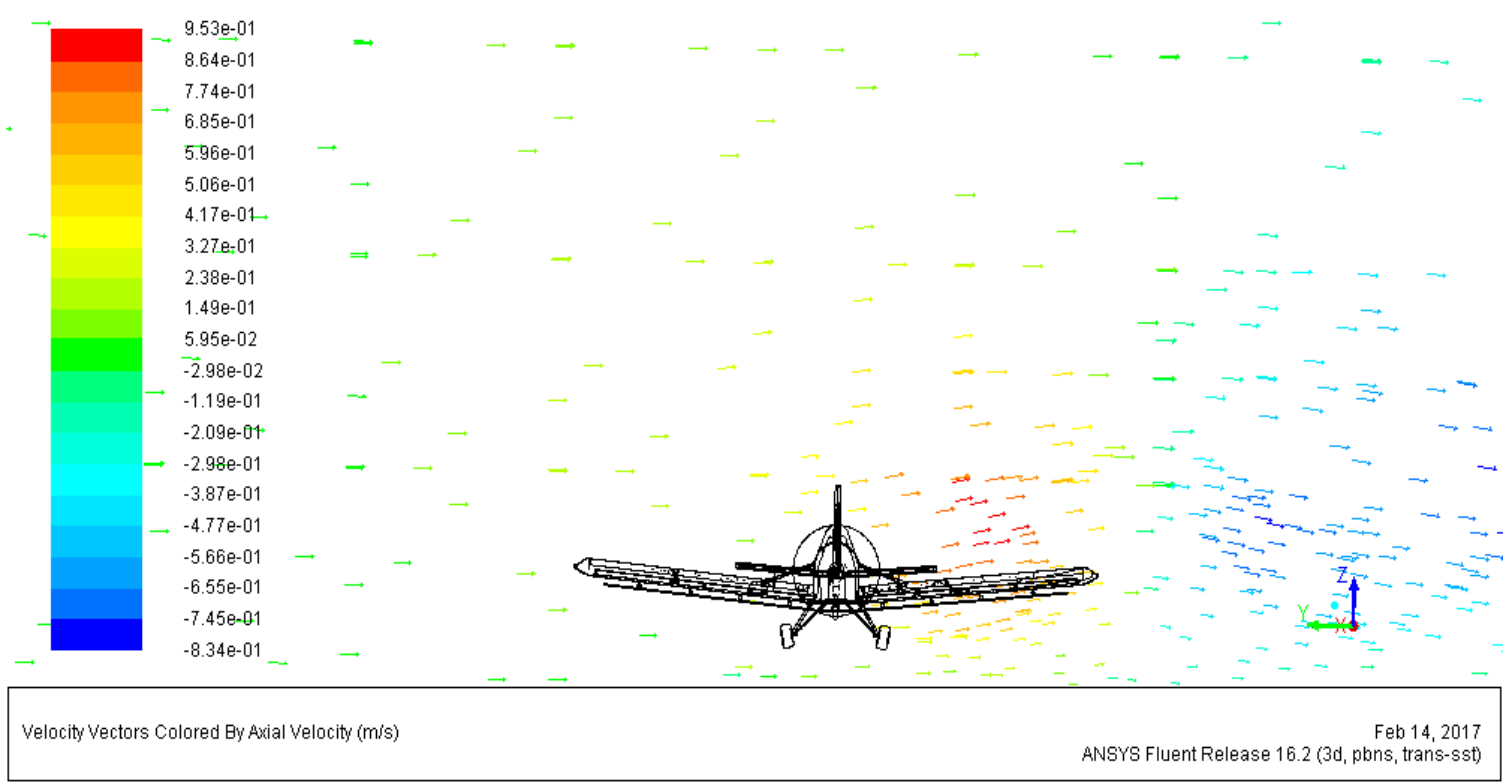

Fig. 9. Vectors of the air velocities in three planes perpendicular to the aircraft velocity in 10, 100 and 200 meters with the wind

First of all, the velocity field, generated by the plane must be presented to show, that the simplifications undertaken in previous models are not appropriate. In the Figures 8. and 9. there are pictures of the field after aircraft in 3 planes - 10, 100 and $200 \mathrm{~m}$ without the wind and the same planes for the airplane with the $5 \mathrm{~m} / \mathrm{s}$ wind.
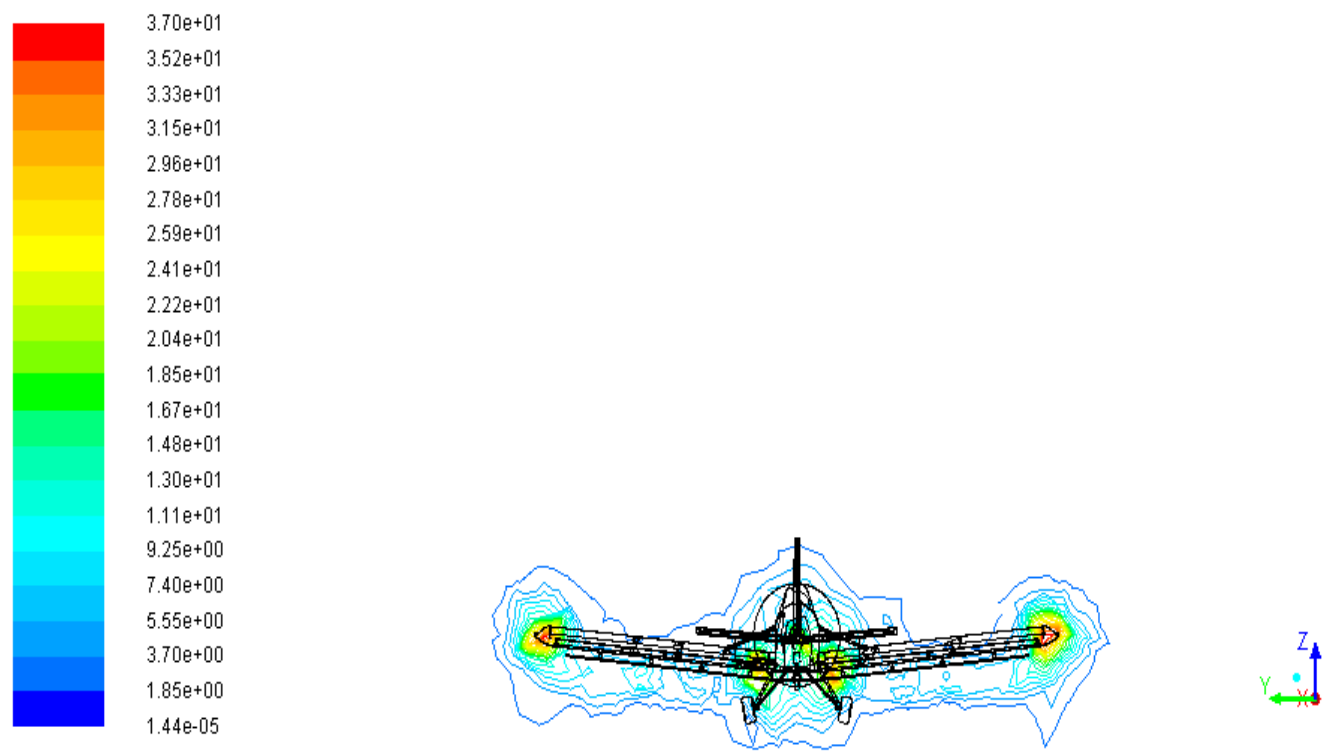

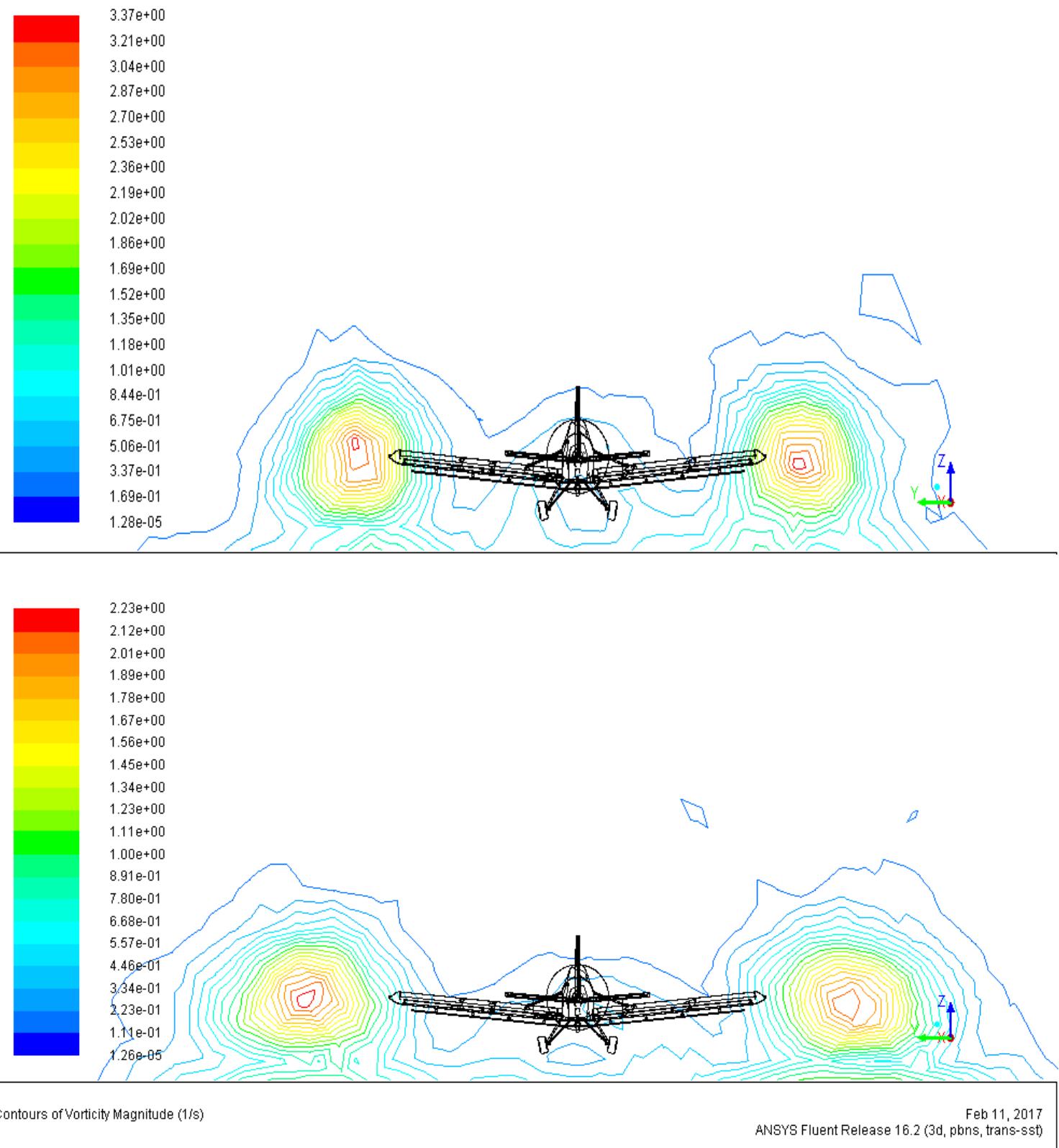

Fig. 10. Contours of the vorticity magnitude in three planes perpendicular to the aircraft velocity in 10 , 100 and 200 meters without the wind

From the first of the pictures it is noticeable, that the symmetry of the velocity field is preserved in the whole domain, but it is not true, that the vorticity lines maintain the whole time in the same position. The lines are shifted towards the external regions from the axis of the symmetry. It is caused by the influence of the ground and must by recognised very carefully. On the other hand, in the case of flight with the wind, it can be noticed the very quick change of the velocity field and the disappearance of such a clear symmetry. 

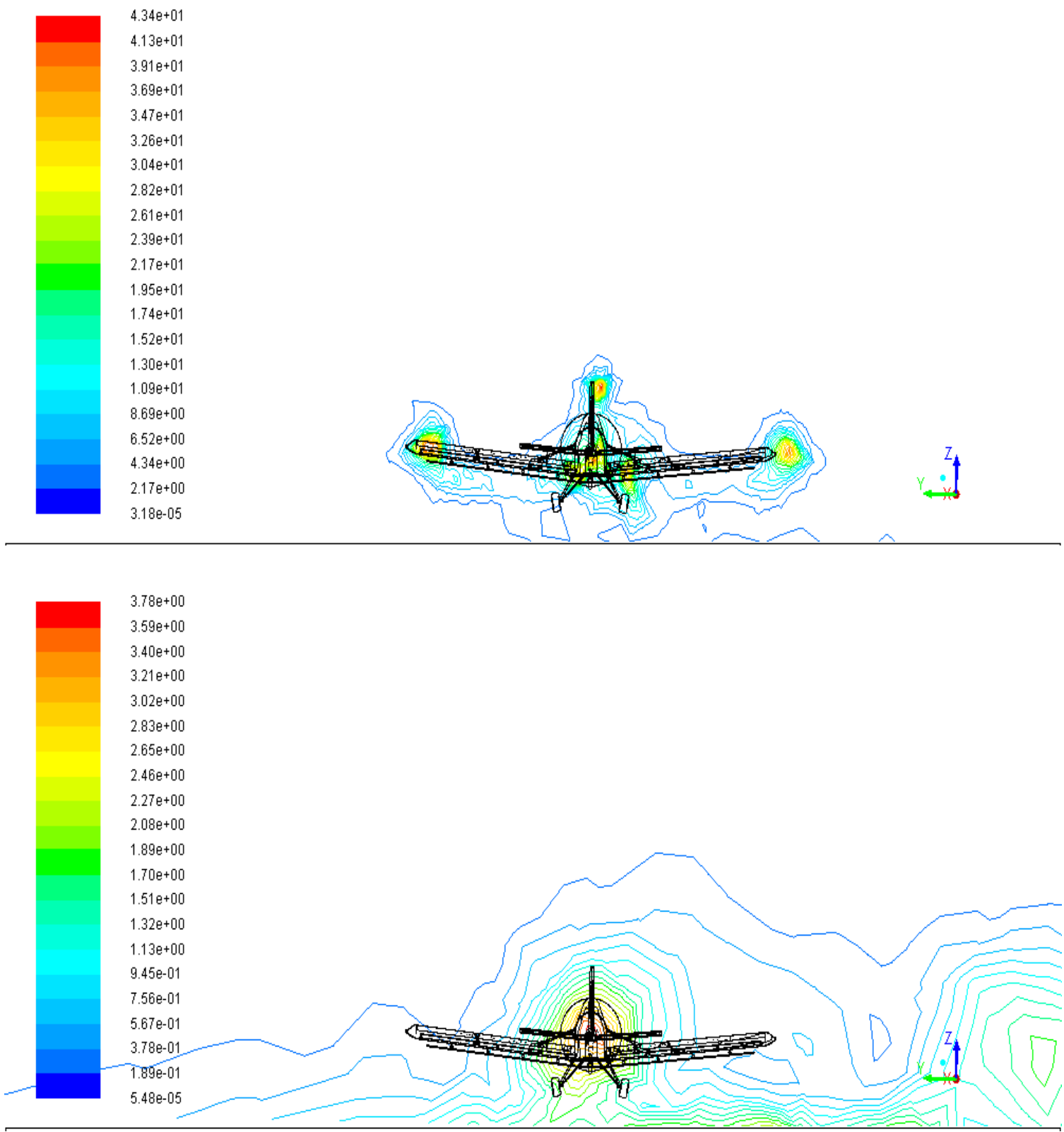


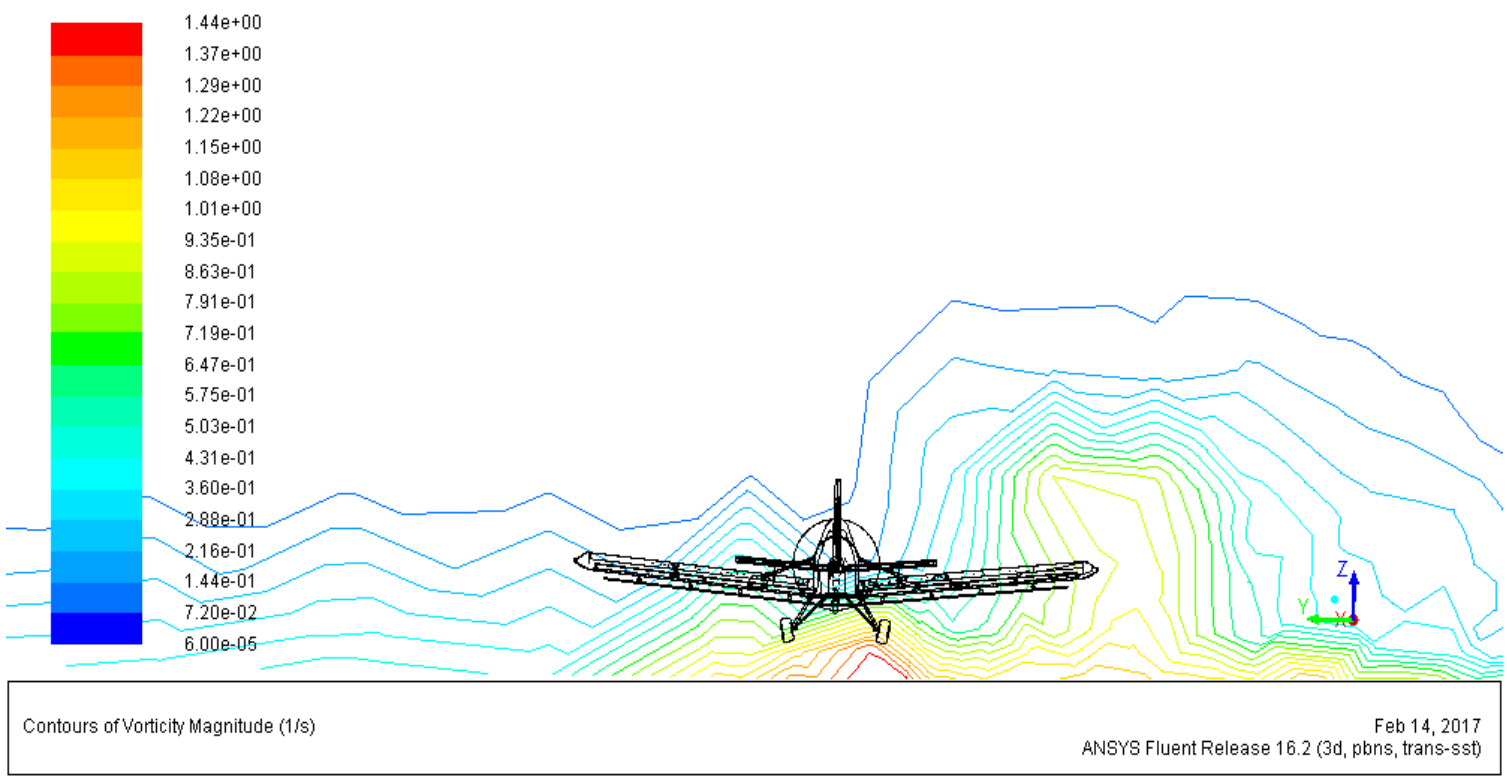

Fig. 11. Contours of the vorticity magnitude in three planes perpendicular to the aircraft velocity in 10 , 100 and 200 meters with the wind

The wind affects such field in a very strong way, the more the farther from the plane. The specific vortex structure disappears in the $50 \mathrm{~m}$ distance behind the aircraft or even faster. Of course, that influence depends on the strength of the wind and its stability during time.

To present the behaviour of the air behind the plane, in the pictures 10. and 11. there are shown contours of the vorticity magnitude in the planes mentioned above. Again it is clear, that the vorticity is greatly disturbed by the wind comparing to the flight without the wind.

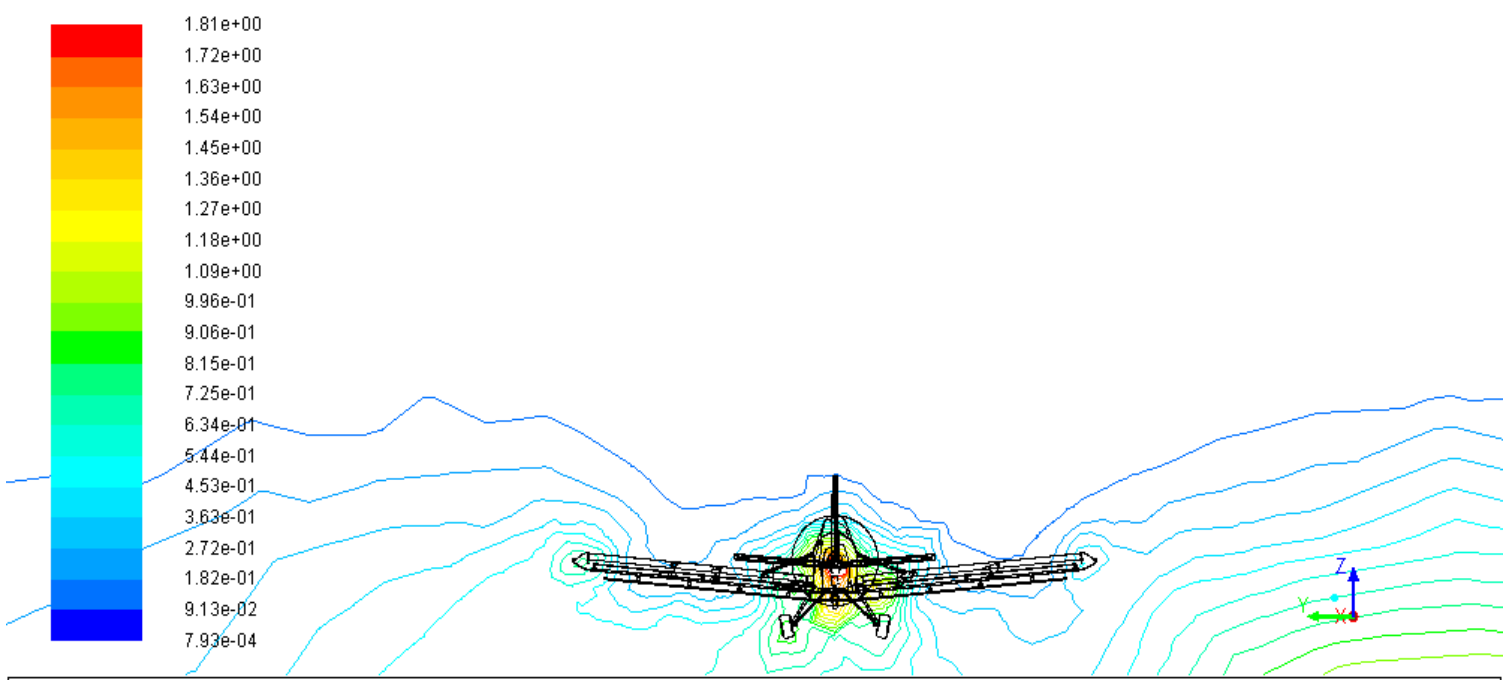



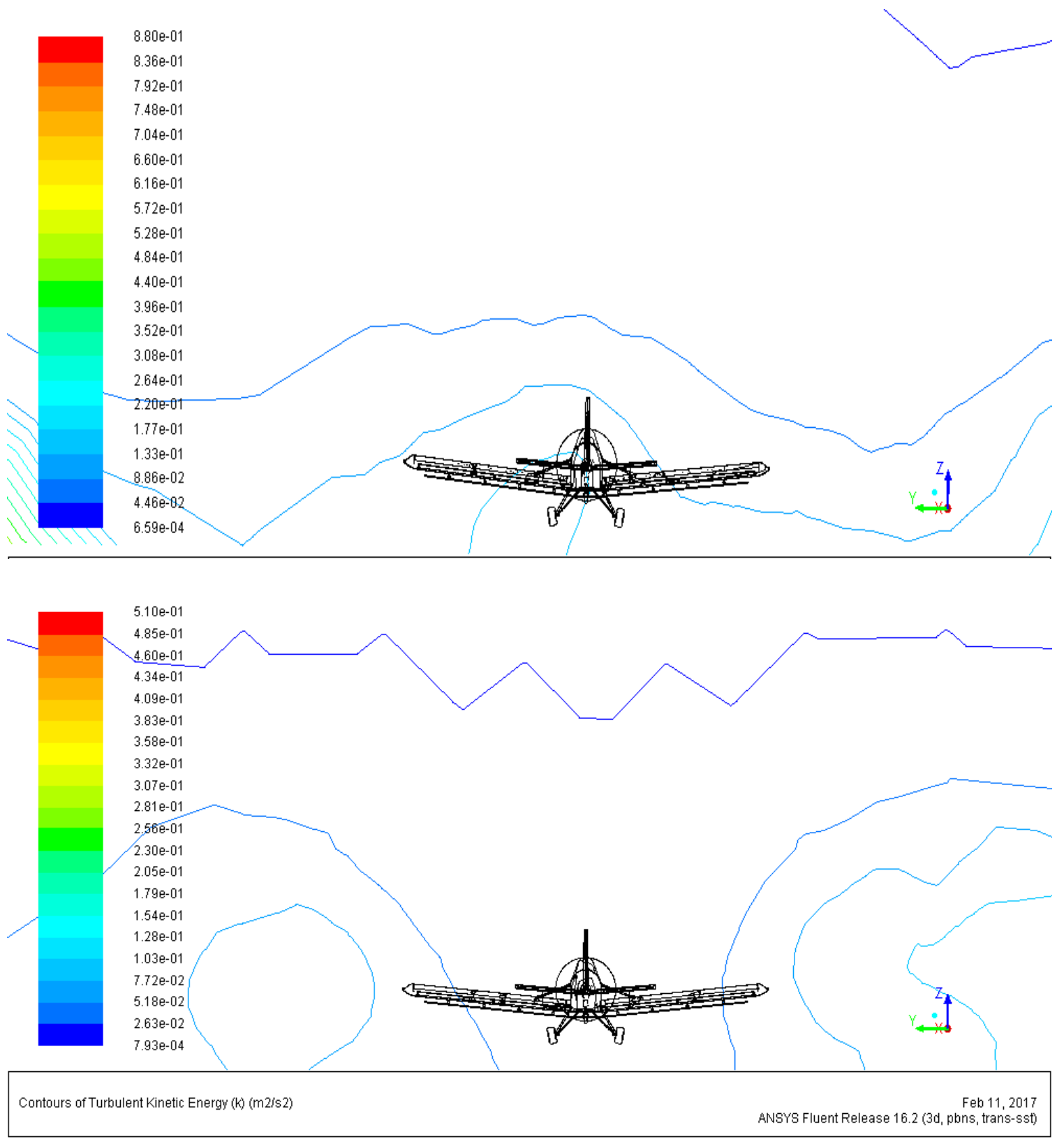

Fig. 12. Contours of the turbulent kinetic energy in three planes perpendicular to the aircraft velocity in 10, 100 and 200 meters without the wind 
Figures 12. and 13. present the contours of the turbulent kinetic energy in two cases: without and with the wind. It can be seen from these, that the main contribution to this energy comes from the fuselage. The wind disturbs the turbulent kinetic energy and generally it disappears very fast in the wake. It means, that the influence of such energy on the movement of the droplets is not as important as the influence of the vorticity, generated by the aircraft in the flight.
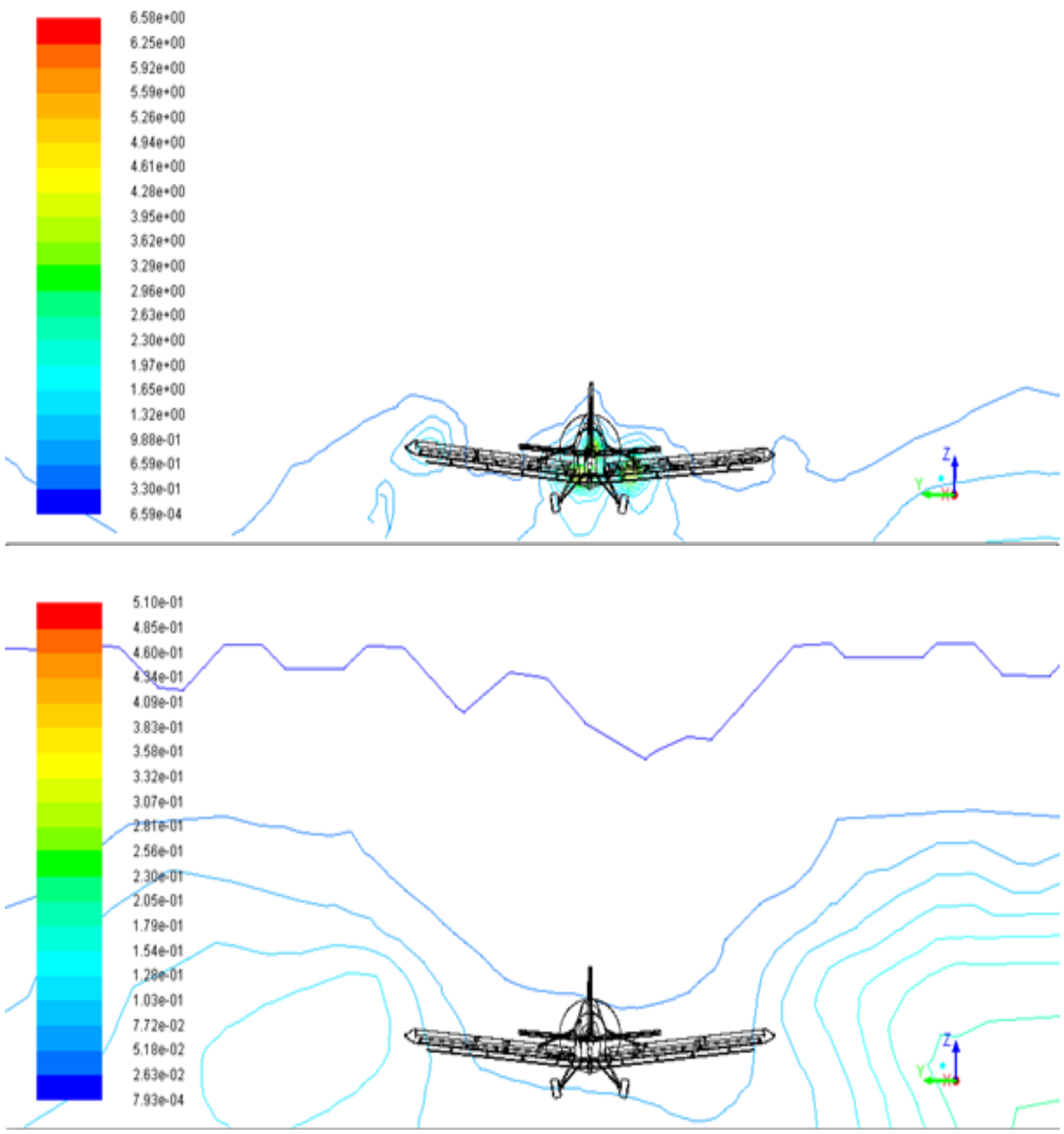


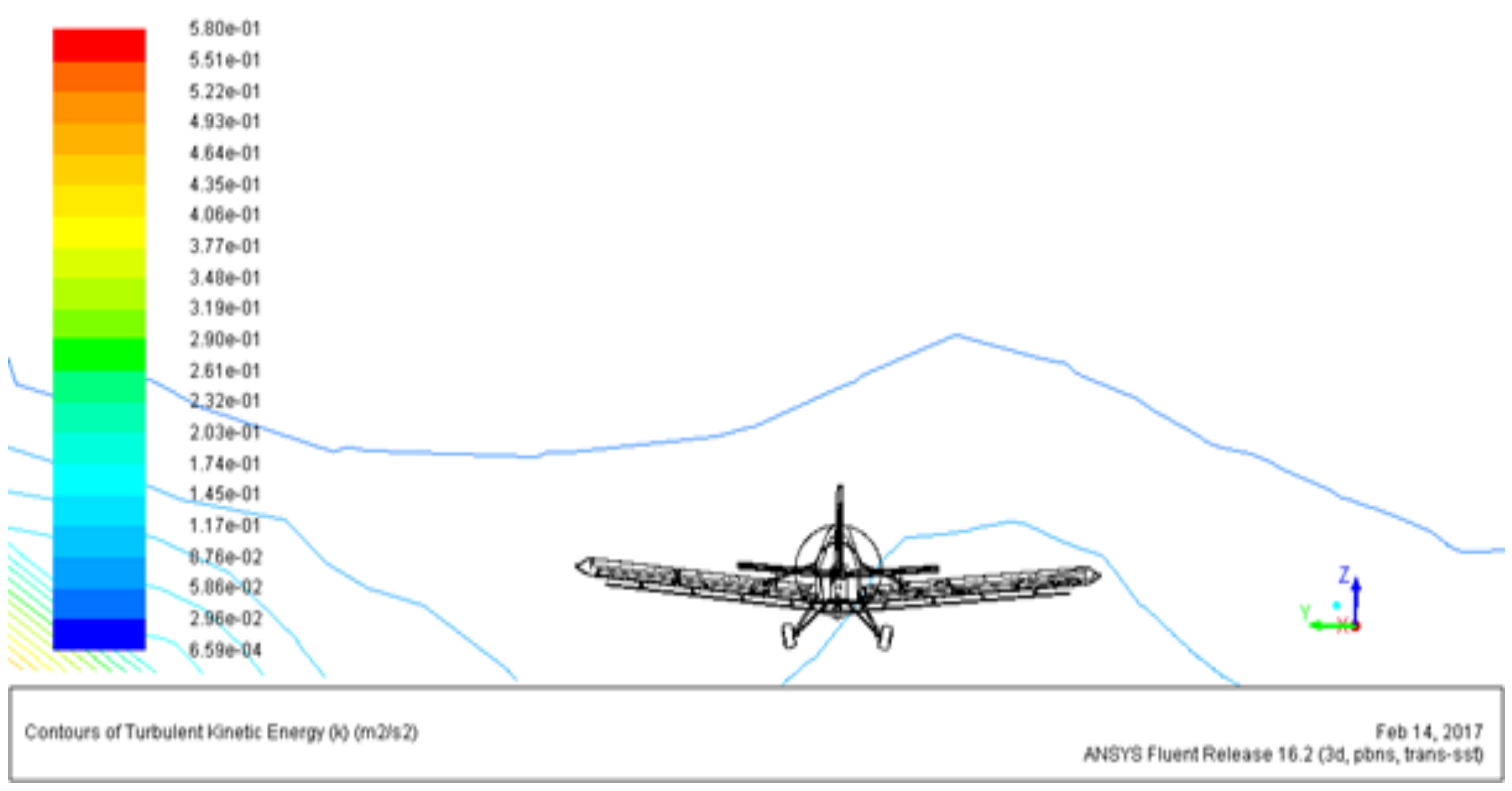

Fig. 13. Contours of the turbulent kinetic energy in three planes perpendicular to the aircraft velocity in 10 , 100 and 200 meters with the wind

In order to show, how the plane generates this energy and how fast the energy dissipates, in the next picture 14., there is a calculation of the turbulent kinetic energy and presentation of it along the distance behind the airplane. The energy exists only very close to the airplane and is not so important for droplets in the longer distance from the aircraft.

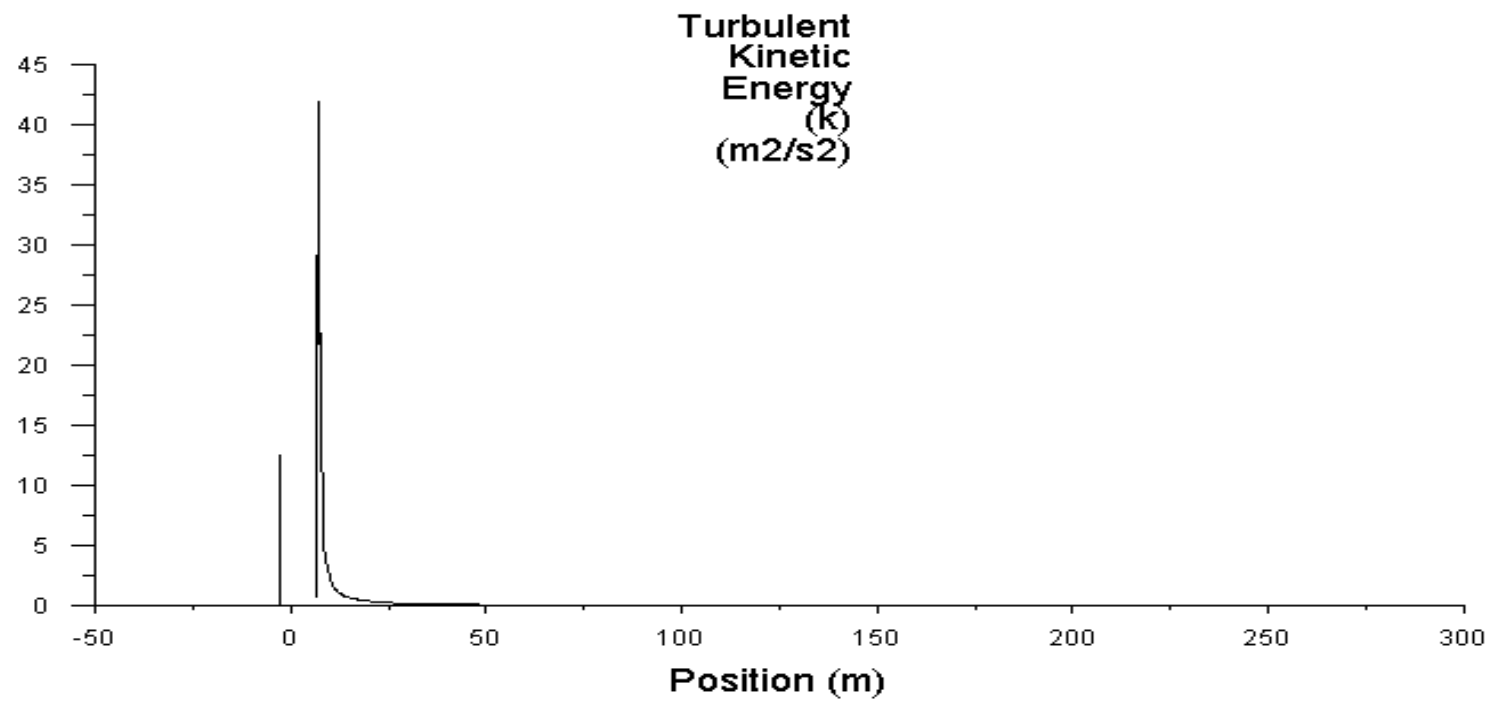

Fig. 14. Turbulent kinetic energy in CFD 
Now the main problem will be considered. Of course, the main aim of the study is to receive the mass distribution on the ground, which can be received, using the 'Kruk' airplane with the agricultural equipment set mounted on it. First of all, it is very convenient to present the contours of the droplets in their diameters distribution. The droplets diameter distribution was set according to studies presented by Micronair for its atomisers and ranges from 10.77 to 320.6 micrometres.

Figures 15. and 17. give the overview of such contours. From the first picture one is able to read the droplets distribution for spraying in the air without the wind. At the beginning, the small droplets are released and they are very quickly intercepted by the air stream. The droplets with greater diameters are more cumulated at the beginning. After a very short time small droplets are caught by the vortices generated by the wing, whereas the bigger ones are falling down due to gravity.

Of course, from the pictures it is readable the general behaviour of the droplets, namely almost all droplets are moving outwardly from the vertical plane oriented with the flight velocity and including aircrafts center of gravity. It means, that more mass is moving in this direction comparing to models with the simple modelling of vortex lines, assuming its fixed position.

The Figure 17. gives the same information, but the plane has the sideslip angle what is caused by the wind. At the beginning, droplets behave in a very similar way, but the situation is changing very soon, what is obvious, having given information about the velocity field behind the aircraft, with and without the wind. The symmetrical structures vanish and the droplets are moving in the wind direction as well as maintaining the rotational movement caused by the swirling air. This rotational movement is not already so clear, as in the previous situation for the flight without the wind, acting on the whole scenario.

Considering the droplets distribution, it is very convenient to analyse the trajectories of droplets released from atomisers. Droplets with three different diameters were chosen and plotted in the planes perpendicular to the flight direction. Figures 16 and 18. present such paths in two cases - with and without the wind for the CFD predictions and, to compare, Figures 19. and 20. give similar trajectories for the AGDISP model. The next picture 21. contains the comparison of the droplet trajectories predictions for only one, chosen diameter, equals $113.7 \mu \mathrm{m}$. This prediction is for the flight without the wind. This scenario is a very meaningful case and is the most illustrative picture of the problem, how the swirling mass of air in the aircraft wake affect the behavior of droplets released form an airplane and falling down due to gravity.

According to the AGDISP model predictions, the paths of the droplets exhibit the regular shape with respect to the plane passing through the axis of the aircraft and are in the form of a quite long helix. It is presented below, in the pictures 19. and 20. Whereas the paths of droplets, which were calculated in our analysis, are quite complicated, what is obvious from the observations. They are presented in the Figure 16. and 18. Comparing to the observations of droplets settling in the air behind the aircraft it is obvious, that such kind of rotating movements never last for so long, to give such a trajectories like helices, especially very near the ground. 

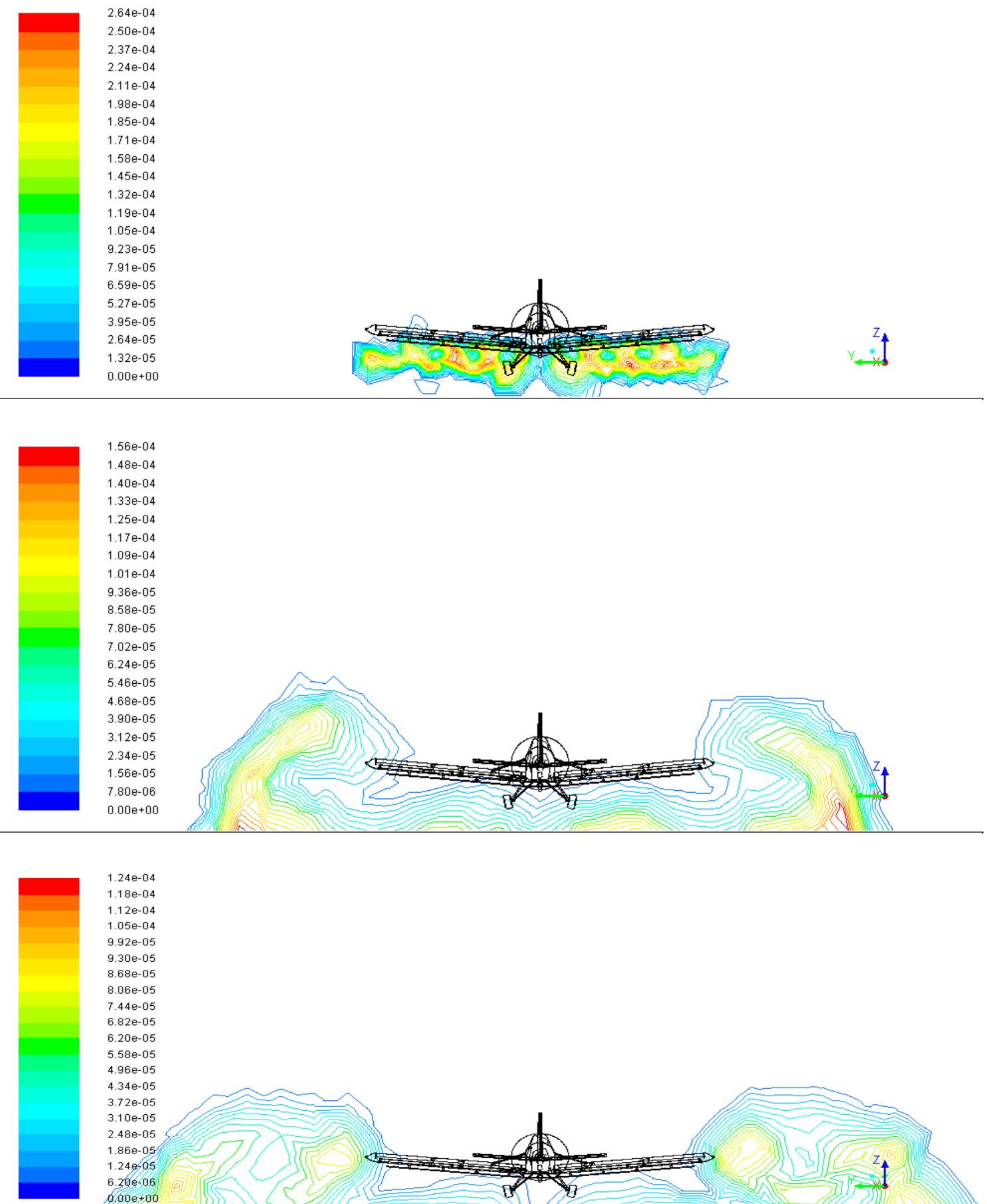

$$
\begin{aligned}
& 1.24 \mathrm{e}-04 \\
& 1.18 \mathrm{e}-04 \\
& 1.12 \mathrm{e}-04 \\
& 1.05 \mathrm{e}-04 \\
& 9.92 \mathrm{e}-05 \\
& 9.30 \mathrm{e}-05 \\
& 8.68 \mathrm{e}-05 \\
& 8.06 \mathrm{e}-05 \\
& 7.44 \mathrm{e}-05 \\
& 6.82 \mathrm{e}-05 \\
& 6.20 \mathrm{e}-05 \\
& 5.58 \mathrm{e}-05 \\
& 4.96 \mathrm{e}-05 \\
& 4.34 \mathrm{e}-05 \\
& 3.72 \mathrm{e}-05 \\
& 3.10 \mathrm{e}-05 \\
& 2.48 \mathrm{e}-05 \\
& 1.86 \mathrm{e}-05 \\
& 1.24 \mathrm{e} 05 \\
& 6.26 \mathrm{e}-06 \\
& 0.00 \mathrm{e}+00
\end{aligned}
$$

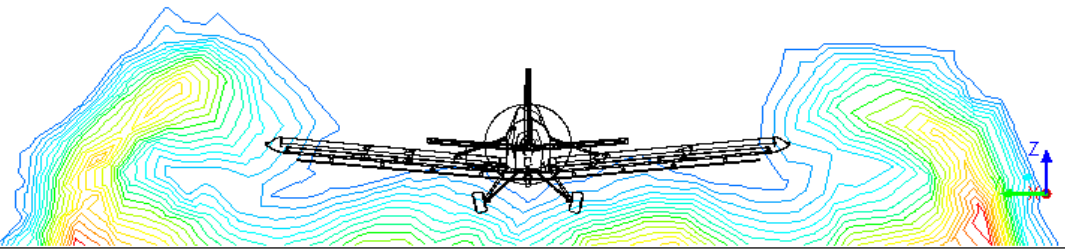

Fig. 15. Contours of the droplets diameters distribution in four planes perpendicular to the aircraft velocity in $10,100,200$ and 500 meters without the wind 


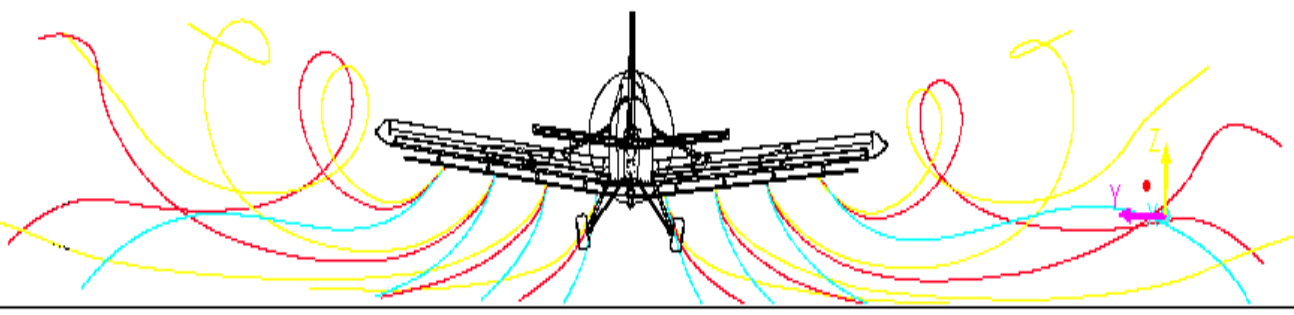

Fig. 16. Flight paths of the droplets with diameters in $\mu \mathrm{m}: 10.77$ - yellow, 113.71 - red, 320.6 - azure, according to CFD without the wind
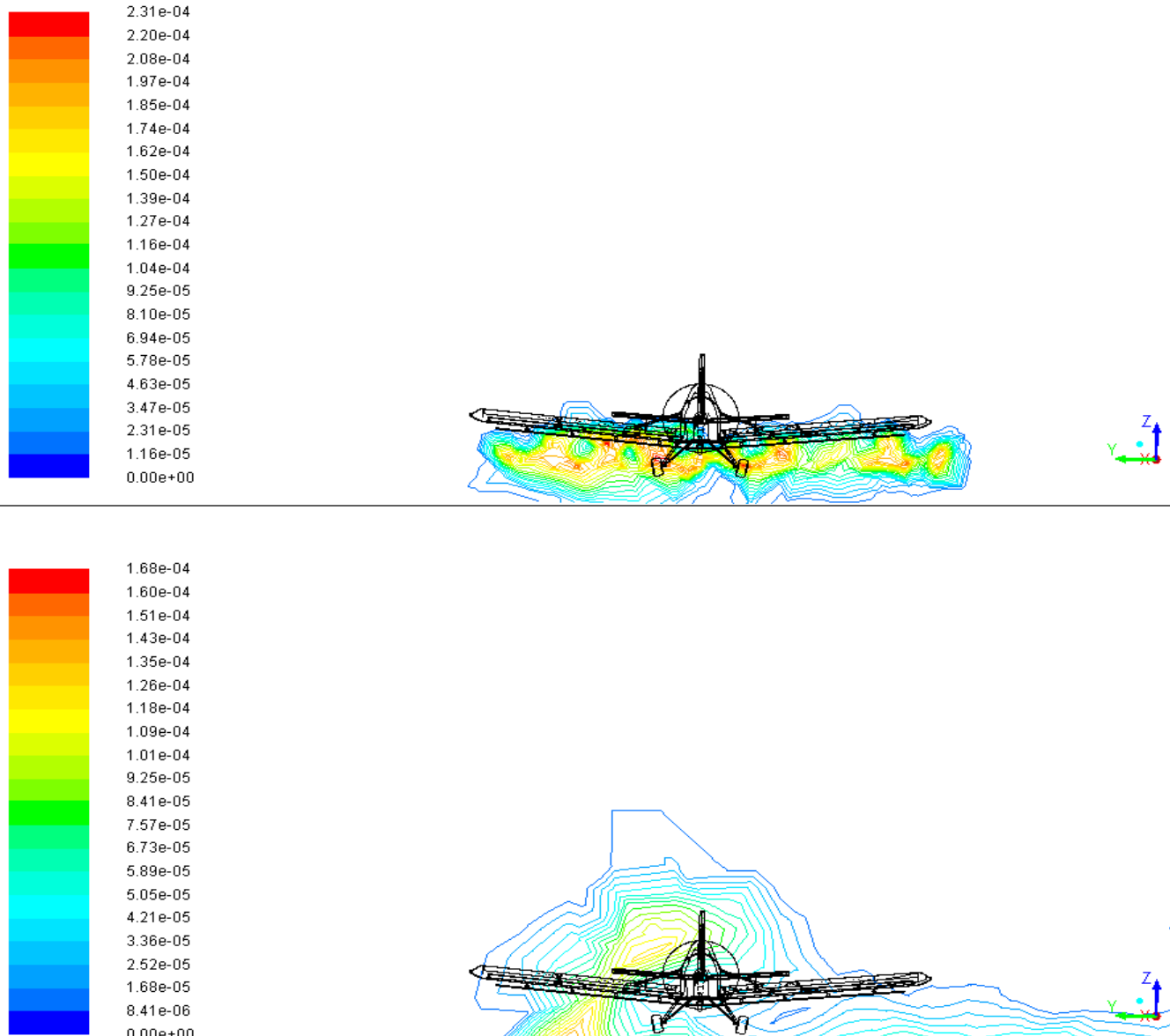

$1.68 \mathrm{e}-04$
$1.60 \mathrm{e}-04$
$1.51 \mathrm{e}-04$
$1.43 \mathrm{e}-04$
$1.35 \mathrm{e}-04$
$1.26 \mathrm{e}-04$
$1.18 \mathrm{e}-04$
$1.09 \mathrm{e}-04$
$1.01 \mathrm{e}-04$
$9.25 \mathrm{e}-05$
$8.41 \mathrm{e}-05$
$7.57 \mathrm{e}-05$
$6.73 \mathrm{e}-05$
$5.89 \mathrm{e}-05$
$5.05 \mathrm{e}-05$
$4.21 \mathrm{e}-05$
$3.36 \mathrm{e}-05$
$2.52 \mathrm{e}-05$
$1.68 \mathrm{e}-05$
$8.41 \mathrm{e}-06$
$0.00 \mathrm{e}+00$

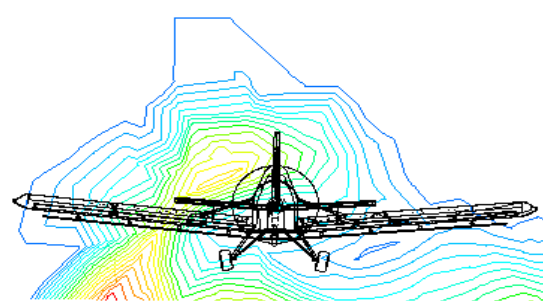




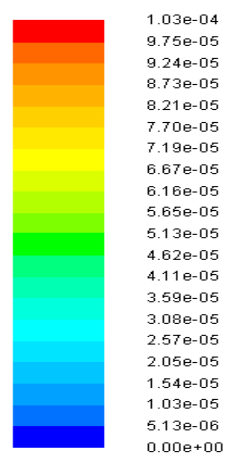

Contours of DPM Diameter (m)

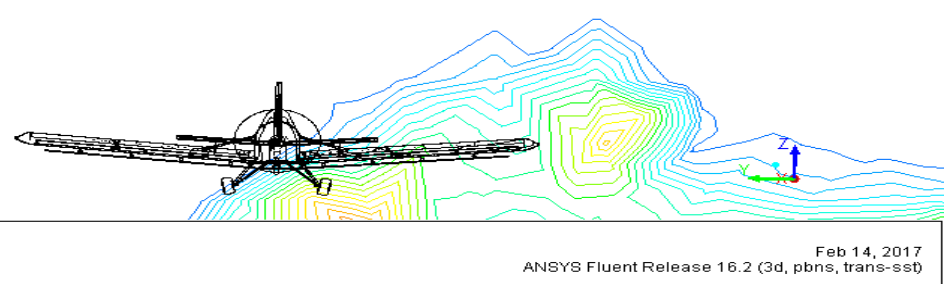

Fig.17. Contours of the droplets diameters distribution in four planes perpendicular to the aircraft velocity in $10,100,200$ and 500 meters with the wind

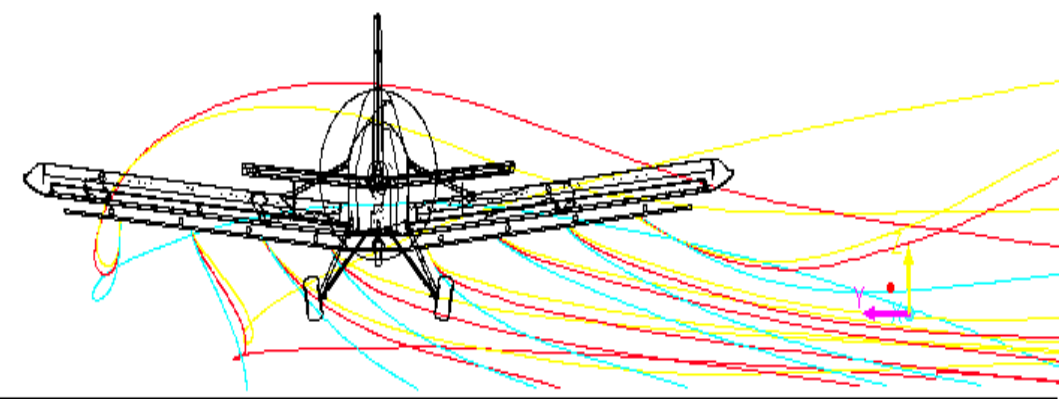

Particle Traces Colored by Particle Diameter (m)

Dec 20,2016

ANSYS Fluent Release 16.2 (3d, pbns, trans-sst)

Fig. 18. Flight paths of the droplets with diameters in $\mu \mathrm{m}$ : 10.77 - yellow, 113.71 - red, 320.6 - azure, according to CFD with the wind

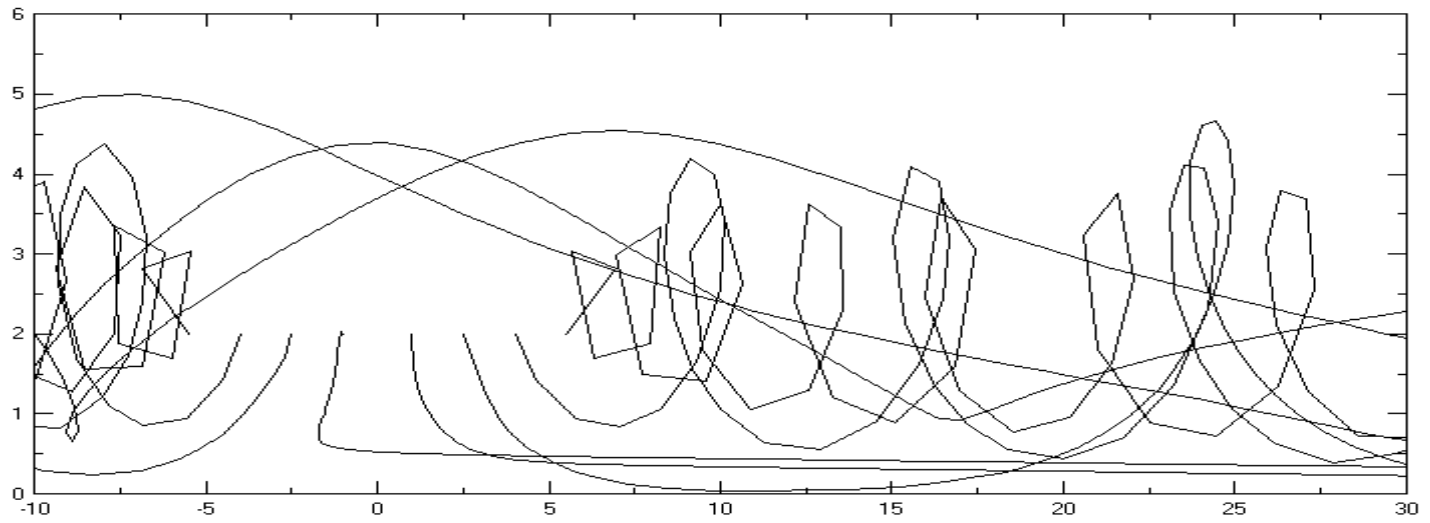

Fig. 19. The flight paths of the droplets according to AGDISP without the wind [37] 


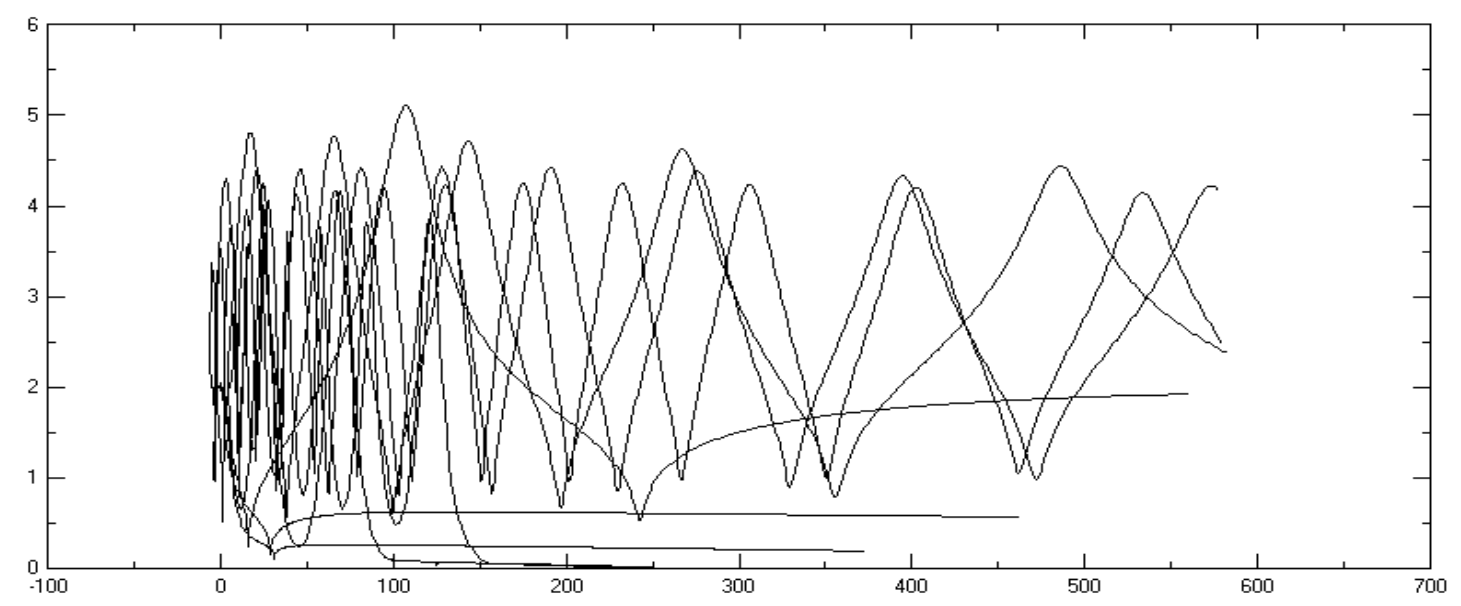

Fig. 20. The flight paths of the droplets according to AGDISP with the wind [37]

From the given previously Figures one can guess immediately, that the picture of trajectories, according to CFD, contrary to AGDISP predictions, is quite different and the CFD model gives the trajectories more disturbed by the wind and without so explicit swirling shape. It is the consequence of the disruption of the symmetrical velocity field behind the plane.

To compare the trajectories of some, ad hoc chosen drops, in the Figure 21. there are presented flight paths for droplets with the 113.7 micrometers diameter, released from four atomizers. They are plotted in the plane YZ, perpendicular to the flight direction. The most visible difference is seen in the position of a loop, according to AGDISP and CFD outcomes. Having in our minds the previous results, it is easy to explain such a difference. The assumptions about the fixed position of the vortex lines, undertaken in AGDISP, give the shifted trajectories into the central regions of the airplane flight path.

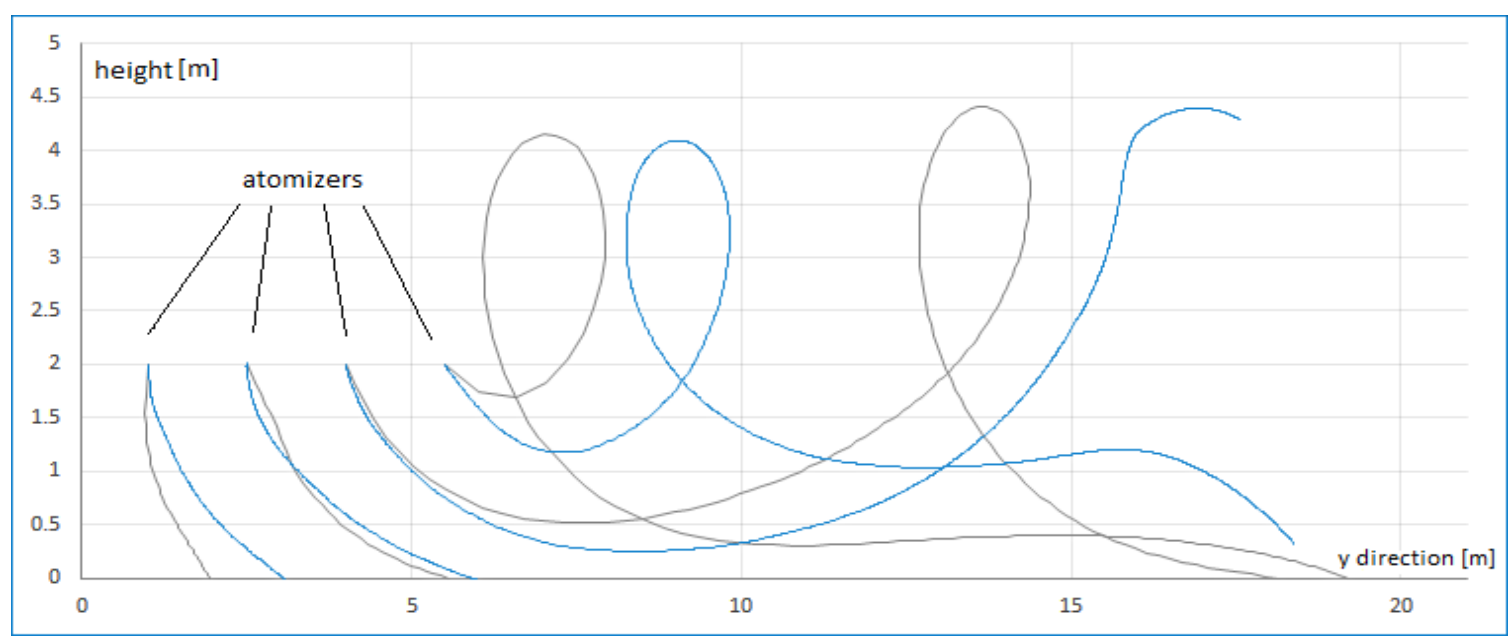

Fig. 21. Flight paths of the droplets with the $113.7 \mu \mathrm{m}$ diameter according to CFD - blue line and AGDISP grey line, without the wind 
Finally, the main aim of this work, which is the total mass fraction of the droplets settled on the ground, is presented below, for the CFD and the AGDISP model predictions. The total mass distribution was calculated for the flight without the wind as well as for the flight with the wind. The authors decided to check as well the influence of the total mass of the airplanes on the droplets mass distribution on the ground. Therefore, the calculations were done for the 'light' and for the 'heavy' 'Kruk'.

The first plot 22. below is for the flight without the slope angle. For AGDISP calculations, it is not possible to set the $0 \mathrm{~m} / \mathrm{s}$ wind. The smallest wind velocity equals $0.2 \mathrm{~m} / \mathrm{s}$ and it is visible in the picture. But generally, it is obvious, that the distribution of the mass is quite different and the influence of the swirling air has here the crucial meaning. The droplets are moved towards outer regions much more in the AGDISP model, than in the CFD one and this is because the two swirls begin to affect droplets immediately after spraying, which is not true.

The second picture 23. below is for presenting the droplets distribution behind the ' Kruk' airplane, fully loaded with fuel and chemicals, flying with the cross wind. The fully loaded airplane means, that there is a fully loaded tank for chemicals, with the $1170 \mathrm{~kg}$ mass and the fully loaded fuel tank, with the $350 \mathrm{~kg}$ mass. Here, the results are similar to the previous conclusions. It is visible very clearly, that for the CFD model, the droplets are pushed through by the vortices and shifted into more distant areas from the aircraft symmetry plane, than in the outcomes, received according to the AGDISP model.

The last picture 24. gives the solutions for droplets, distributed in the case of the flight without chemicals and only with the half-empty fuel tank. The situation is almost the same as in the fully loaded airplane. Taking into account all the described results a conclusion imposes itself, that the influence of the velocity field behind the plane in the flight is very important and complicated and only fully recognized and described, with the appropriate boundary conditions, may give acceptable results.

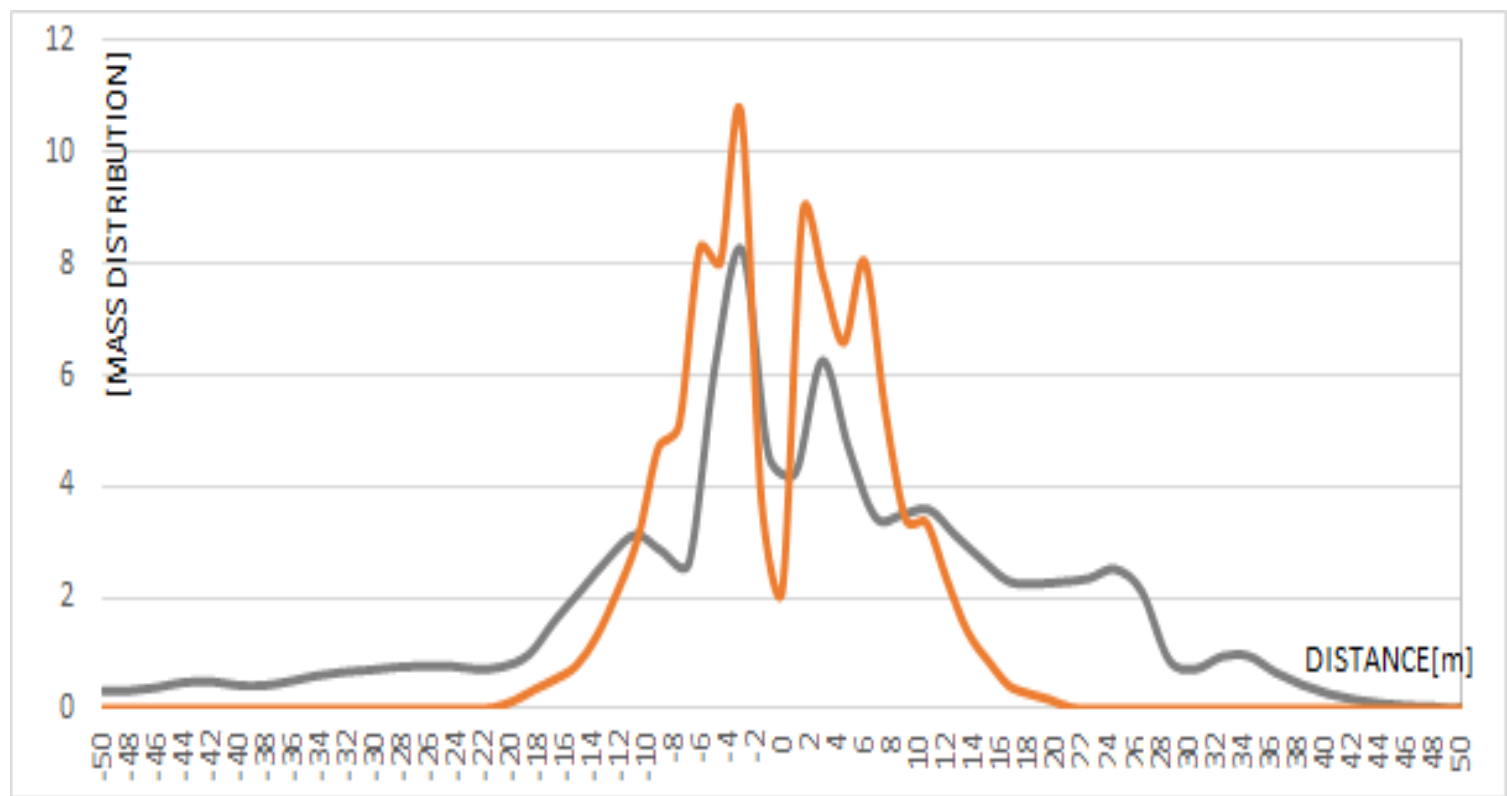

Fig. 22. The comparison of the droplets mass fraction prediction for the fully loaded airplane with the $0.2 \mathrm{~m} / \mathrm{s}$ wind according to CFD - orange line, AGDISP - grey line 


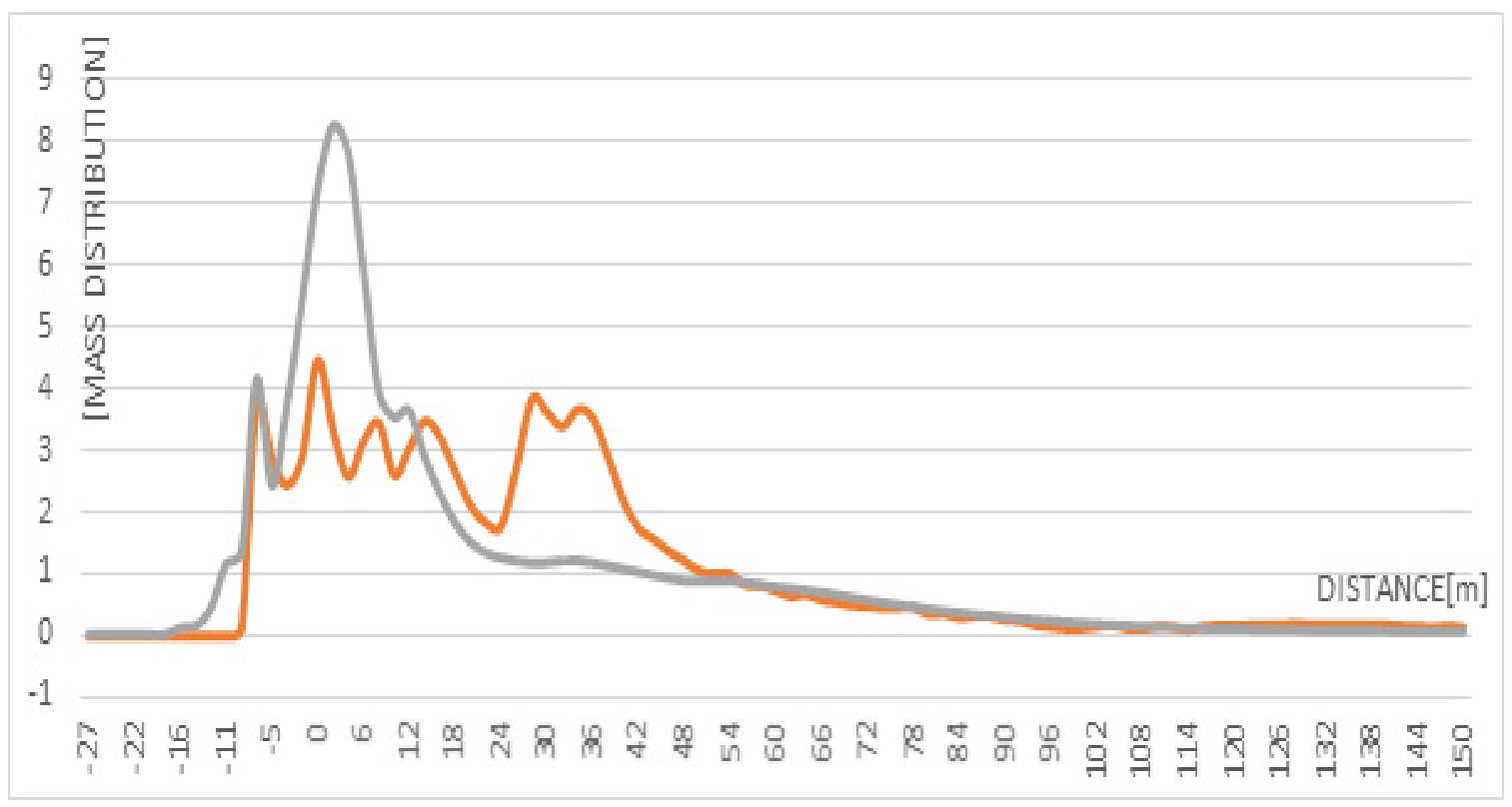

Fig. 23. The comparison of the droplets mass fraction prediction for the fully loaded airplane with the wind according to CFD - orange line, AGDISP - grey line

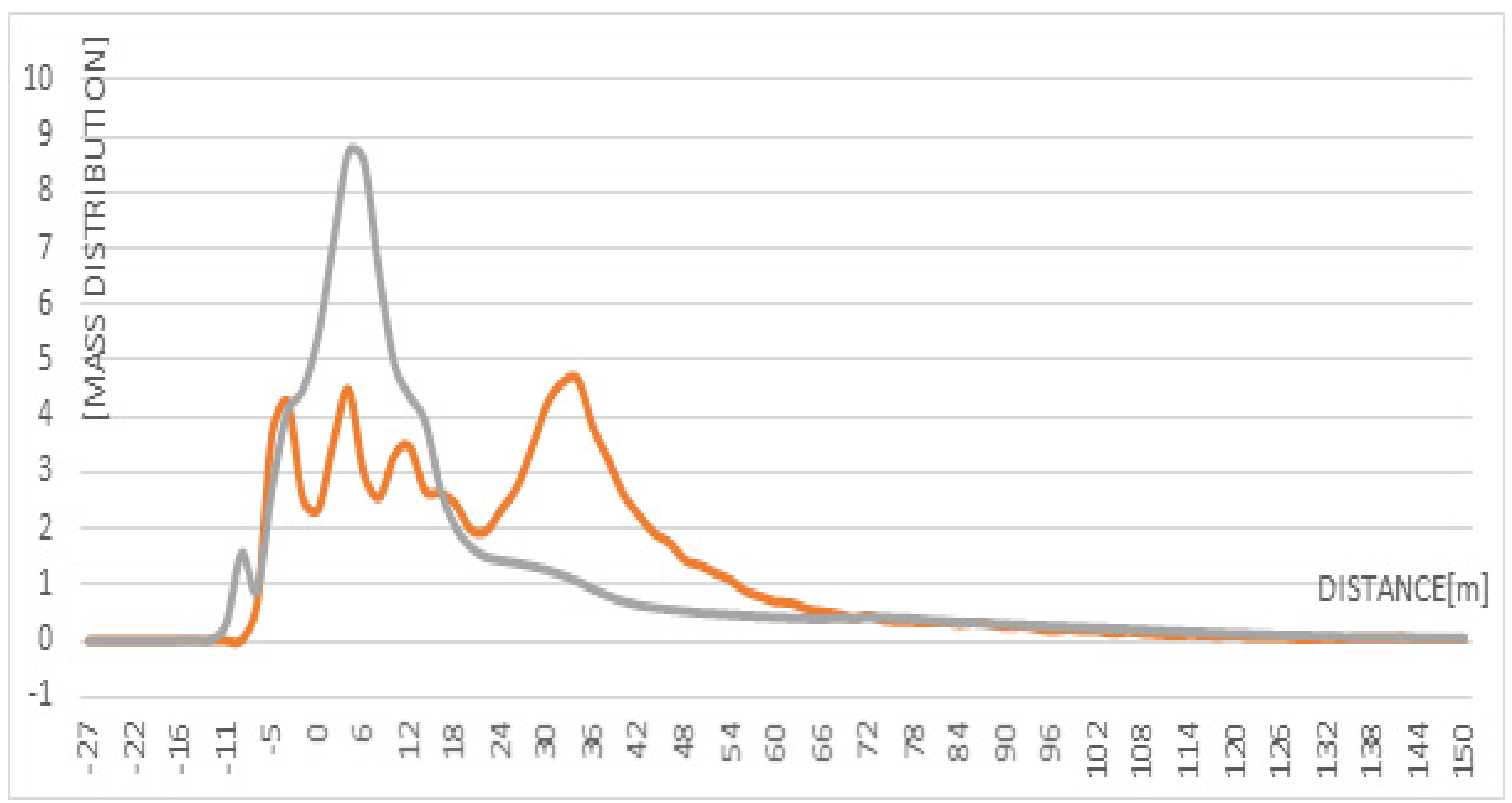

Fig. 24. The comparison of the droplets mass fraction prediction for the empty airplane with the wind according to CFD - orange line, AGDISP - grey line 


\section{MAJOR CONCLUSIONS}

The first important study of the behavior of droplets released from aircraft, where the authors used CFD Reynolds-averaged Navier-Stokes (RANS) models, for a Lagrangian (droplet phase) and Eulerian (fluid phase) procedure, to predict droplet trajectories through a turbulent aircraft wake, was done for the Air Tractor AT-802 airplane [33]. The authors of the present study have analyzed the spray of droplets from the PZL-106BT 'Turbo Kruk' agricultural airplane, by means of RANS calculations, using the Discrete Phase Model (DPM) method. The three-dimensional full-scale CFD model of the aircraft and surrounding air has been created. The airflow was modeled as a continuous Eulerian fluid and the droplets were tracked in the Lagrangian frame. The RANS models demonstrated very important influence of the flow field, generated by the airplane on droplets. The our results were compared to AGDISP predictions.

After recalculation, the need for the further study is highly noticeable. Firstly, the modeled results, which were obtained from the CFD calculations, should be consistent with experimental data. It is very crucial and useful to be in possession of such data. However, there is still a compulsion to implement the physics of flow around aircraft to a more advanced degree, through the refinement of the geometry of the physical situation. Secondly, such theoretical analysis and their improvements provide a low-cost alternative to field experiments, aiming to optimize the lateral distribution of sprayed droplets. Finally, further research, both theoretical and experimental, is needed to produce a higher degree of conformity between results given by the mathematical and computational models and field tests. In the authors' opinion the final step in the development of such research seems to be exactly the Computational Flow Dynamics calculations.

\section{BIBLIOGRAPHY}

[1] Ashley, H. and Landahl, M.T., I965, Aerodynamics of Wing and Bodies, Reading Addison-Wesley Publishing Co.

[2] Atias, M. and Weihs, D., 1984, "Motion of Aircraft Trailing Vortices Near the Ground”, Journal of Aircraft, 21(10), pp. 783-786.

[3] Bache, D.H. and Sayer, W.J.D., 1975, “Transport of Aerial Spray. A Model of Aerial Dispersion”, Agricultural Meteorology, 15, pp. 257-271.

[4] Bilanin, A.J., Teske, M.E. and Barry, J.W., 1989, "AgDisp: the Aircraft Spray Dispersion Model, Code Development and Experimental Validation”, Trans. ASAE, 32, pp. 327-334.

[5] Bird, S.L., Perry, S.G., Ray, S.L. and Teske, M.E., 2002, "Evaluation of the AgDISP Aerial Spray Algorithms in the AgDRIFT Model”, Environ. Toxicol. Chem., 21, pp. 672-681.

[6] Boothroyd, R.G., 1971, Flowing Gas-Solid Suspensions, London: Chapman and Hall.

[7] Bragg, M.B., 1986, "A Numerical Simulation of the Dispersal of Liquids from Aircraft", Trans. of the ASAE, 29, pp. 10-15.

[8] SAS IP, 2013, ANSYS Fluent Theory Guide, ANSYS.

[9] Cramer, H.E., Bjorklund, J.R., Record, E.A., Dumbauld, R.K., Swanson, R.N., Faulkner, J.E. and Tingle, A.G., 1972, "Development of Dosage Models and Concepts", Report DTCTR-72-609-1. Dugway, Utah: U.S. Army, Dugway Proving Ground.

[10] Аеревянко, В.С., 1974, ВАияние аэродинамических возмущений на процессы авиационного опыливания и опрыскивания, Москва: Транспорт.

[11] Duan, B., Yenodol, W.G. and Mierzejewski, K., 1992, "Statistical Comparison of the AGDISP Model with Deposit Data”, Atmos. Environ. A, 26(9), pp. 1635-1642. 
[12] Dumbauld, R.K., Bjorklund, J.R. and Saterlie, S.F., 1980, "Computer Models for Prediction Aircraft Spray Dispersion and Deposition Above and Within Forest Canopies: User's Manual for the FSCBG Computer Program”, Report 80-11. Davis, Cal.: USDA Forest Service.

[13] Dziubiński, A., Jaśkowski, P., Seredyn, T., 2016 "CFD Analysis of Agricultural Aircraft Aerodynamic Characteristics”, Transactions of the Institute of Aviation, No. 4(245), pp. 321-337.

[14] Dziubiński, A., Stalewski, W. and Żółtak, J., 2008, "Examples of Fluent Applications in Helicopter Flight Safety Analysis” (in Polish: „Przykłady zastosowania pakietu Fluent w analizach bezpieczeństwa lotu śmigłowców”), Transactions of the Institute of Aviation, No. 194-195, pp. 146-157.

[15] ESDU No. 72026, 1972, Characteristics of the Wind Speed in the Lower of the Atmosphere Near the Ground: Strong Winds, London: Neutral Atmosphere.

[16] Frost, W. and Huang, K.H., 1981, "Monte Carlo Model for Aircraft Applications of Pesticides", ASAE Paper No. 811507., St. Joseph, Mich.: ASAE.

[17] Gaidos, R.E., Patel, M.R., Valcore, D.L. and Fears, R.D., 1990, "Prediction of Spray Drift Deposition from Aerial Applications of Pesticides”, ASAE Paper No. AA90007., St. Joseph, Mich.: ASAE/NAAA.

[18] Harvey, J.K. and Perry, F.J., 1971, "Flow Field Produced by Trailing Vortices in the Vicinity of Ground”, AIAA Journal, 9(8), pp. 1659-1660.

[19] Hewitt, A.J., 2001, "Drift Filtration by Natural and Artificial Collectors: A Literature Review", Stewart Agricultural Research Services Inc.

[20] Himel, C.M., Loats, H. and Bailey, G.W., 1990, "Pesticide Sources to the Soil and Principles of Spray Physics”, Madison: SSSA Book Series 2. Wisc.: SSSA, pp. 7-50.

[21] Kamiński, S., 1970, „Problems of Spray Drift in Plant Protection Treatments Performed by Aviation Technique” (in Polish: „Analiza parametrów charakteryzujących rozpylanie ciekłych środków ochrony roślin”), Report 4.31.15, Institute of Aviation, Warszawa.

[22] Leonard, A., 1980, "Vortex Methods for Slow Simulation", Journal of Computational Physics, No. 37, pp. 289-335.

[23] Łusiak, T., Dziubiński, A. and Szumański, K., 2009, "Interference between helicopter and its surroundings, experimental and numerical analysis", TASK QURTAERLY, No. 13(4), p. 379-392.

[24] Miranda, L.R., Elliot, R.D. and Baker, W.M., 1977, “A Generalized Vortex Lattice Method for Subsonic and Supersonic Flow Applications", NASA CR 2865.

[25] Moore, D.W., 1974, "A Numerical Study of the Roll-up of a Finite Vortex Sheet”, Journal of Fluid Mechanics, No. 63(2), pp. 225-235.

[26] Pietruszka, J., 1987, „Simulation of Spraying Performer by M18 Aircraft” (in Polish: „Symulacja procesu opryskiwania wykonanego z samolotu M18”), Mielec: Sprawozdanie nr OLO-4/99/87. OBR SK - not published.

[27] Pietruszka, J., 1987, “Computer Simulation of Spraying from Aircraft” (in Polish: „Symulacja komputerowa procesu opryskiwania z samolotu”), Ph.D. thesis, Politechnika Warszawska.

[28] Pietruszka, J. and Rowiński, R.S., 2004, "Computer Simulation of Aerial Spraying” Annual Review of gricultural Engineering, No. 3(1), pp. 125-140.

[29] Ranz, W.E. and Marschall, W.R., 1952, "Evaporation from Drops”, Chemical Engineering Progress, 48(3), pp. 141-146 and Chemical Engineering Progress, 48(4), pp. 173-180.

[30] Reed, W.H., 1954, "An Analytical Study of the Effect of Airplane Wake on the Lateral Dispersion of Aerial Sprays", NACA Report 1196.

[31] Rowiński, R.S., 1993, "Problems of Spray Drift in Plant Protection Using Aviation Techniques", Acta Acad. Agricult. Techn. Olst. Aed., No. 16, pp. 171-195. 
[32] Rowiński, R.S. and Ferenc, M., 200o, "Some Problems Concerned with the Theory of Drift", Annual Review of Agricultural Engineering, No. 2(1), pp. 148-156.

[33] Ryan, S.D., Gerber, A.D. and Holloway, A.G.L., 2013, "A computational Study on Spray Dispersal in the Wake of an Aircraft", Trans. ASABE, No. 56(3), pp. 847-868.

[34] Saputro, S. and Smith, D.B., 1990, "Expert System for Aerial Spray Drift", ASAE Paper No. 901018. St. Joseph, Mich.: ASAE.

[35] Seredyn, T.P., 2014, "Experimental Investigations of a Drifting Cloud of Droplets Dispersed from Aircraft”, Archive of Mechanical Engineering, No. 3, pp. 393-407.

[36] Sobczak, K., 2008, „CFD Modeling of Chosen Helicopter Flight Phases in Fluent” (in Polish: „Modelowanie wybranych przypadków lotu śmigłowca z wykorzystaniem oprogramowania Fluent”), Transactions of the Institute of Aviation, No. 194-195, pp. 158-165.

[37] Teske, M.E., Bird, S.L., Esterly, D.M., Curbishley, T.B., Ray, S.L. and Perry, S.G., 2002, "AgDRIFT: a Model for Estimating Near-field Spray Drift from Aerial Applications”, Environ. Toxicol. and Chem., No. 21(3), pp. 659-671.

[38] Teske, M.E. and Thistle, H.W., 2003, "Release Height and Far-Field Limits of Lagrangian Aerial Spray Models", Trans. ASAE No. 46(4), pp. 977-983.

[39] Teske, M.E., Thistle, H.W. and Ice, G.G., 2003, "Technical Advances in Modeling Aerially Applied Sprays", Trans. ASAE No. 46(4), pp. 985-996.

[40] Teske, M.E., Thistle, H.W. and Londergan, R.J., 2011a, "Modification of Droplet Evaporation in the Simulation of Fine Droplet Motion Using AGDISP”, Trans. ASAE No. 54(2), pp. 417-421.

[41] Teske, M.E., Thistle, H.W., Schou, W.C., Miller, P.C.H., Strager, J.M., Richardson, B., Butler, M.C., Barry, J.W., Twardus, D.B. and Thompson, D.G., 2011b, "A Review of Computer Models for Pesticide Deposition Prediction”, Trans. ASAE No. 54(3), pp. 789-801.

[42] Trayford, R.S. and Welch, L.W., 1977, "Aerial Spraying: A Simulation of Factors Influencing the Distribution and Recovery of Liquid Droplets", Journal of Agricultural Engineering Research, No. 22, pp. 183-196.

[43] Wallace, D.J., Picot, J.J.C. and Chapman, T.J., 1995, "A Numerical Model for Forestry Aerial Spraying", Agric. Forestry Meteorology, No. 76, pp. 19-40.

[44] Wickens, R.H., 1977, "Calculation of Wake Vortex Trajectories for Low Flying Spraying Aircraft”, Canada: National Aero Report LTR-LA-215 Nat. Res. Council.

[45] Williamson, R.E. and Threadgill, E.D., 1974, "A Simulation for the Dynamics of Evaporating Spray Droplets in Agricultural Spraying”, Trans. ASAE, No. 17(2), pp. 254-261.

[46] http://www.microngroup.com

[47] http://www.jetphotos.com

[48] http://www.epa.gov 


\section{ANALIZY CFD ROZKŁADU KROPEL ROZPRZESTRZENIANYCH ZA POMOCĄ STATKU POWIETRZNEGO}

\section{Streszczenie}

W artykule opisano analizy numeryczne, wykorzystujące współczesne metody CFD, do badania przestrzennego rozkładu kropel cieczy, rozpylonych w polu prędkości samolotu 'Turbo Kruk' w odległości do $500 \mathrm{~m}$ za statkiem powietrznym. Wykorzystano równania RANS, celem rozwiązania zagadnienia Lagrangea trajektorii kropel (dyskretnych cząstek) w powietrzu (płyn), rozumianym jako sturbulizowany ślad aerodynamiczny samolotu. Wybrana i opisana metoda w pracy posiada ogromny potencjał, możliwy do wykorzystania w celu ulepszenia obecnych, obowiązujących modeli opryskiwania z samolotu i ustalenia lepszych procedur technologicznych. W pracy wykorzystano metody CFD do opisania i analizy zjawiska rozpylania kropel przez atomizery, zamocowane na płatowcu. Podjęto problem wpływu wiatru bocznego na struktury wirowe, generowane lecącym statkiem powietrznym, a przez to na trajektorie kropel i rozkład przestrzenny masy oprysku. Pokazano, że taki wpływ jest niedoszacowany według obecnych, standardowych modeli, przede wszystkim poprzez porównanie do wyników uzyskanych w oparciu o model AGDISP.

Słowa kluczowe: modelowanie oprysków, analizy CFD, ślad aerodynamiczny samolotu. 